\title{
Effect of increased potassium intake on cardiovascular risk factors and disease: systematic review and meta-analyses
}

\author{
(a) (1) $\Theta$ OPEN ACCESS
}

\author{
Nancy J Aburto scientist ${ }^{1}$, Sara Hanson intern ${ }^{1}$, Hialy Gutierrez independent consultant ${ }^{2}$, Lee \\ Hooper senior lecturer in research synthesis and nutrition ${ }^{3}$, Paul Elliott professor ${ }^{4}$, Francesco $\mathrm{P}$ \\ Cappuccio Cephalon professor of cardiovascular medicine \& epidemiology ${ }^{5}$
}

\begin{abstract}
${ }^{1}$ Nutrition Policy and Scientific Advice Unit, Department of Nutrition for Health and Development, World Health Organization, 20 Avenue Appia, 1211 Geneva 27, Switzerland; ${ }^{2} 200$ Wheeler Avenue, Staten Island, NY 10314, USA; ${ }^{3}$ Norwich Medical School, University of East Anglia, Norwich NR4 7TJ, UK; ${ }^{4}$ Department of Epidemiology and Biostatistics and MRC-HPA Centre for Environment and Health, Imperial College London, London, UK; ${ }^{5}$ World Health Organization Collaborating Centre for Nutrition, Warwick Medical School, Coventry CV2 2DX, UK
\end{abstract}

\begin{abstract}
Objective To conduct a systematic review of the literature and meta-analyses to fill the gaps in knowledge on potassium intake and health.

Data sources Cochrane Central Register of Controlled Trials, Medline, Embase, WHO International Clinical Trials Registry Platform, Latin American and Caribbean Health Science Literature Database, and the reference lists of previous reviews.

Study selection Randomised controlled trials and cohort studies reporting the effects of potassium intake on blood pressure, renal function, blood lipids, catecholamine concentrations, all cause mortality, cardiovascular disease, stroke, and coronary heart disease were included.

Data extraction and synthesis Potential studies were independently screened in duplicate, and their characteristics and outcomes were extracted. When possible, meta-analysis was done to estimate the effects (mean difference or risk ratio with 95\% confidence interval) of higher potassium intake by using the inverse variance method and a random effect model.

Results 22 randomised controlled trials (including 1606 participants) reporting blood pressure, blood lipids, catecholamine concentrations, and renal function and 11 cohort studies (127 038 participants) reporting all cause mortality, cardiovascular disease, stroke, or coronary heart disease in adults were included in the meta-analyses. Increased potassium intake reduced systolic blood pressure by 3.49 (95\% confidence interval 1.82 to 5.15$) \mathrm{mm} \mathrm{Hg}$ and diastolic blood pressure by 1.96 (0.86 to 3.06$) \mathrm{mm} \mathrm{Hg}$ in adults, an effect seen in people with hypertension but not in those without hypertension. Systolic blood
\end{abstract}

pressure was reduced by 7.16 (1.91 to 12.41$) \mathrm{mm} \mathrm{Hg}$ when the higher potassium intake was 90-120 mmol/day, without any dose response. Increased potassium intake had no significant adverse effect on renal function, blood lipids, or catecholamine concentrations in adults. An inverse statistically significant association was seen between potassium intake and risk of incident stroke (risk ratio $0.76,0.66$ to 0.89 ). Associations between potassium intake and incident cardiovascular disease (risk ratio $0.88,0.70$ to 1.11 ) or coronary heart disease $(0.96$, 0.78 to 1.19 ) were not statistically significant. In children, three controlled trials and one cohort study suggested that increased potassium intake reduced systolic blood pressure by a non-significant $0.28(-0.49$ to 1.05$)$ $\mathrm{mm} \mathrm{Hg}$.

Conclusions High quality evidence shows that increased potassium intake reduces blood pressure in people with hypertension and has no adverse effect on blood lipid concentrations, catecholamine concentrations, or renal function in adults. Higher potassium intake was associated with a $24 \%$ lower risk of stroke (moderate quality evidence). These results suggest that increased potassium intake is potentially beneficial to most people without impaired renal handling of potassium for the prevention and control of elevated blood pressure and stroke.

\section{Introduction}

Non-communicable diseases are the leading cause of death globally, killing more people each year than all other causes combined..$^{1-3}$ Elevated blood pressure and hypertension are major risk factors for cardiovascular diseases, especially coronary heart disease, stroke, and heart failure, as well as renal failure. ${ }^{4}$ Although non-communicable diseases disproportionately affect adults, they and their risk factors are becoming more prevalent 
in paediatric populations. Diet related non-communicable diseases may take years or decades to manifest, and delaying the onset of these diseases could improve lives and result in substantial cost savings. ${ }^{56}$ Much of the human and social impact caused each year by morbidity and mortality related to non-communicable diseases could be averted through interventions that are well understood, cost effective, and feasible. ${ }^{1}$

Potassium is an essential nutrient that is needed for maintenance of total body fluid volume, acid and electrolyte balance, and normal cell function. ${ }^{7}$ In the pre-agricultural and post-agricultural diets of our human ancestors, potassium intake was very high, often exceeding $200 \mathrm{mmol} / \mathrm{day}{ }^{8}{ }^{8}$ In modern society, these levels have been markedly reduced. Food processing reduces the potassium content of food, and a diet high in processed foods and low in fresh fruits and vegetables is often lacking in potassium. ${ }^{8}$ Data from around the world suggest that the average potassium consumption in many countries is below $70-80 \mathrm{mmol} / \mathrm{day},{ }^{9}$ the value recommended by the 2002 Joint World Health Organization (WHO)/Food and Agriculture Organization Expert Consultation, ${ }^{10}$ and even fewer countries report an average consumption of $90 \mathrm{mmol} /$ day as recommended by countries such as the United Kingdom, Spain, Mexico, and Belgium. ${ }^{11-14}$ No countries report an average population consumption of $120 \mathrm{mmol} /$ day as recommended by the United States, Canada, Republic of Korea, and Bulgaria. ${ }^{15-17}$ Lower potassium consumption has been associated with elevated blood pressure, hypertension,,$^{18}$ and stroke, ${ }^{19}$ and higher levels of consumption could be protective against these conditions. ${ }^{10}$

Public health interventions aimed at increasing potassium intake from food are, therefore, potential cost effective measures for reducing the burden of morbidity and mortality from non-communicable diseases. However, the evidence on the potential beneficial effect of increased potassium on blood pressure and cardiovascular disease is not entirely consistent. Three systematic reviews with meta-analyses, all published 10 or more years ago, suggest that increased potassium intake lowers blood pressure in adults with and without hypertension. ${ }^{20-22}$ Another systematic review without meta-analysis also concluded that increased potassium decreased blood pressure in adults. ${ }^{23}$ However, one meta-analysis of studies that included only people with hypertension reported no significant effect of increased potassium intake on blood pressure..$^{24} \mathrm{~A}$ recent meta-analysis of 11 cohort studies reported an inverse association between potassium intake and risk of stroke but found no association with cardiovascular disease or coronary heart disease..$^{19}$ No systematic reviews have looked at the effect of increased potassium intake on potential adverse effects such as changes in blood lipid concentrations, catecholamine concentrations, and renal function in adults or children, or of the effect of increased potassium intake on blood pressure in children. Additionally, none of the previous reviews or meta-analyses attempted to determine the optimal level of intake of potassium for maximum health benefits.

To inform the development of its guideline on potassium intake, the WHO initiated this review to systematically compile results from studies in apparently healthy adults and children without acute illnesses or renal impairment that could compromise handling of potassium and to conduct meta-analyses to answer the following questions. (1) What is the effect of increased potassium intake compared with lower intake on blood pressure, all cause mortality, cardiovascular disease, stroke, and coronary heart disease in apparently healthy adults? (2) What is the effect of increased potassium intake on blood pressure in apparently healthy children? (3) What is the effect of increased potassium intake on the potential adverse effects of changes in blood lipid concentrations, catecholamine concentrations, and renal function in apparently healthy adults and children? (4) What is the level of potassium intake that results in the maximum benefit on blood pressure and risk of mortality and cardiovascular diseases? (5) Is the effect of increased potassium differentially affected by the hypertension status of the population, sex, average sodium or potassium intake at baseline, type of intervention, type of device or method used to measure blood pressure, study design, or duration of intervention?

\section{Methods}

We conducted this review according to the methods recommended by the Cochrane Collaboration and documented the process and results in accordance with the preferred reporting items for systematic reviews and meta-analyses (PRISMA) statement for reporting systematic reviews. ${ }^{25} 26$

\section{Outcome data}

The primary outcomes of interest in adults were blood pressure, all cause mortality, and all incident, fatal, and non-fatal cardiovascular disease, stroke, and coronary heart disease. We also examined potential adverse effects such as changes in blood lipid concentrations (total cholesterol, low density lipoprotein cholesterol, high density lipoprotein cholesterol, triglyceride concentrations), catecholamine concentrations, and renal function and any other adverse effects reported by study authors. The primary outcomes in children were blood pressure and the potential adverse effects of changes in blood lipids or catecholamine concentrations and any other adverse effects reported by study authors.

\section{Inclusion criteria}

We planned to include only randomised controlled trials (both individual and cluster randomised). Knowing that some outcomes would probably not have at least three studies meeting the inclusion criteria, we decided a priori that in the event of an insufficient number of randomised controlled trials for a given outcome (less than three), we would include quasi-randomised trials, non-randomised trials, and prospective observational cohort studies. Randomised and non-randomised controlled trials must have allocated at least one group of participants to increased potassium intake (intervention) and one group to lower potassium intake (control) for at least four weeks. Cohort studies must have had a prospective design that measured potassium intake as the exposure and reported at least one of the outcomes of interest after at least one year of follow-up. Randomised controlled trials (but not cohort studies) had to use urinary potassium excretion from 24 hour urine collections to estimate actual potassium intake. The controlled trials could not have concomitant interventions (that is, non-drug interventions, antihypertensive drugs, or other drugs) in the intervention group unless those interventions were also applied to the control group, so the only difference between the groups was the level of potassium intake. We excluded studies targeting acutely ill or HIV positive people, people admitted to hospital, or people with impaired urinary potassium excretion due to a medical condition or drug treatment.

\section{Search strategy}

We first searched the literature for high quality systematic reviews of randomised controlled trials or cohort studies on the effect of increased potassium intake relative to lower potassium intake on the outcomes of interest. We examined the reference 
lists of included studies of an identified review if the inclusion criteria were in agreement with, or were broader than, the inclusion criteria defined for the specific objectives of our review. We reviewed each original reference and compared it against the inclusion criteria for our review and included those that met our inclusion criteria.

We did a complete search of the literature on potassium intake and the outcomes of interest published since the data search of the identified systematic review(s). We searched the Cochrane Central Register of Controlled Trials (6 September 2011), Medline (28 August 2011), Embase (25 August 2011), the WHO International Clinical Trials Registry Platform (1 September 2011), and the Latin American and Caribbean Health Science Literature Database (LILACS) (1 September 2011). Our search had no language restrictions or additional limits. We examined the reference lists of included studies for additional studies. Two reviewers independently screened the output of the search to identify potentially eligible studies. Complete data search terms can be found in the supplementary material (online supporting materials (OSM) 1).

\section{Data extraction, risk of bias, and quality assessment}

Two reviewers independently extracted relevant population and intervention characteristics of each study by using a standard data extraction form. A third reviewer checked extracted data, and all disagreements were resolved through consensus. We requested any relevant missing information from the original study authors. In the case of duplicate publications and companion papers of a primary publication, we evaluated all available data to maximise the yield of information.

For randomised controlled trials, we assessed the risk of bias associated with the method of sequence generation (possible selection bias), allocation concealment (possible selection bias), blinding (possible performance bias), selective reporting (possible selective reporting bias), loss to follow-up (possible attrition bias), and completeness of reporting outcome data (possible attrition bias). In cohort studies, we additionally evaluated the risk of bias associated with methods of measuring exposure (possible bias due to confounding or contamination), collecting outcome data (possible bias due to inadequate duration of exposure and performance bias), and selecting study participants (possible bias due to lack of comparability between groups). We rated the risk of bias as being low, unclear, or high according to established criteria. ${ }^{25} 27$

We used funnel plots to assess for the presence of small study bias. ${ }^{28}{ }^{29}$ We generated "risk of bias graph" and "risk of bias summary" figures for each study type separately in adults and children. We used GRADEProfiler software (version 3.6) to assess the quality of the body of evidence according to the methodology of grading of recommendations assessment, development, and evaluation (GRADE) ${ }^{30}$

\section{Statistical analysis}

One reviewer entered data into Review Manager software (Copenhagen, 2011), and a second reviewer checked data entry for accuracy. In cases of disagreement, a third reviewer also evaluated the data and all reviewers made a conclusion based on consensus.

In the randomised controlled trials conducted in adults, we estimated potassium intake from 24 hour urinary excretion by using a conversion factor of $1.3 .^{31}$
We calculated an overall effect estimate for all dichotomous data as a risk ratio with $95 \%$ confidence interval. We extracted dichotomous data in the form of a risk ratio or a hazard ratio from each original cohort study by using the statistical models that controlled for the greatest number of covariates (to reduce bias) without controlling for blood pressure, because blood pressure explains some of the effect that potassium has on non-communicable disease related outcomes. We compared the risk of each outcome in the group with the highest potassium intake against that of the group with the lowest potassium intake (reference group) to generate an overall effect estimate. We did a subgroup analysis to test the effect of different levels of intake on outcomes and used different intake levels from the same study compared with the same reference group but did not pool the subgroups.

For randomised controlled trials, we generated an overall effect estimate for all continuous variables by using the difference in means, with $95 \%$ confidence intervals, between the intervention and the control groups. When a trial had more than one intervention group but only one control group, we used the group with the highest potassium intake in the analysis.

When original study authors assessed outcomes at more than one time point, we included the data from the latest time point in overall analyses and used data from all relevant time points in the subgroup analysis based on study duration. We used the inverse variance method random effects meta-analysis to combine data and generate the overall effect estimate. ${ }^{32}$ For all analyses, we considered results to be statistically significant at $\alpha=0.05$.

We assessed heterogeneity by visual inspection of the forest plots and with the $\mathrm{I}^{2}$ statistic quantifying inconsistency across studies. ${ }^{33} \mathrm{We}$ considered an $\mathrm{I}^{2}$ statistic of $75 \%$ or greater to be an important level of inconsistency. When we found heterogeneity, we combined data in a meta-analysis, noted the heterogeneity, and examined characteristics of individual studies and subgroups and attempted to explain the heterogeneity.

We defined the following subgroups during the protocol development with input from the WHO Nutrition Guidelines Expert Advisory Group to test specific objectives: achieved potassium intake in intervention or comparison group $(<90$ $\mathrm{mmol} /$ day $v$ 90-120 $\mathrm{mmol} /$ day $v 120-155 \mathrm{mmol} /$ day $v>155$ $\mathrm{mmol} / \mathrm{day}$ ) (note: original studies reported urinary potassium excretion; using a conversion factor of 1.3$),{ }^{31} 70 \mathrm{mmol} /$ day urinary potassium equals approximately $90 \mathrm{mmol} /$ day potassium intake, $90 \mathrm{mmol} /$ day urinary potassium equals $120 \mathrm{mmol} / \mathrm{day}$ intake, and $120 \mathrm{mmol} /$ day urinary potassium equals 155 $\mathrm{mmol} /$ day intake); achieved difference in potassium intake between intervention or comparison and control ( $<30 \mathrm{mmol} / \mathrm{day}$ $v 30-60 \mathrm{mmol} /$ day $v>60 \mathrm{mmol} /$ day); average potassium intake at baseline ( $<50 \mathrm{mmol} /$ day $v 50-80 \mathrm{mmol} /$ day $v>80 \mathrm{mmol} /$ day $)$; average sodium intake at baseline $(<2 \mathrm{~g} /$ day $v 2-4 \mathrm{~g} /$ day $v>4$ $\mathrm{g} /$ day); hypertensive status of participants at baseline (with hypertension $v$ without hypertension $v$ undetermined or mixed); and sex (male $v$ female $v$ mixed). Additional subgroups in randomised controlled trials only were: type of intervention (diet or feeding $v$ supplementation $v$ advice); type of device used to measure blood pressure (automatic $v$ manual); method of measurement of blood pressure (supine office $v$ seated office $v$ standing office $v$ unspecified); study design (parallel $v$ crossover); and duration of intervention ( $<2$ months $v$ 2-4 months $v>4$ months). We also planned to use these subgroups to examine reasons for heterogeneity.

We did a sensitivity analysis to examine the effect of removing studies at high risk of bias from the analysis. For randomised 
controlled trials, we considered a study to be at high risk of bias if it was graded as inadequate in both the randomisation and concealment of allocation and in either blinding or loss to follow-up. For cohort studies, we considered a study to be at high risk of bias if the measurement method for estimating potassium intake was a single 24 hour dietary recall or if the study had high risk of confounding for both measurement method and a second reason.

\section{Results}

\section{Search results}

We identified 5310 publications reporting on blood pressure, blood lipids, or catecholamine concentrations in adults or children or on renal function, all cause mortality, cardiovascular disease, stroke, or coronary heart disease in adults. Of these, we found 5250 in the electronic search and 60 in the references from published systematic reviews or other sources. ${ }^{19-24}$ After we eliminated duplicate publications, clearly irrelevant publications, and studies that did not reach basic inclusion criteria, we assessed 75 full text publications for eligibility. We excluded 31 studies on full text review. We could not determine the eligibility of seven randomised controlled trials from the published manuscripts; we requested additional information that we have not yet received. ${ }^{35-41}$ We could not pool data from two studies because they lacked the necessary quantitative information. ${ }^{42}{ }^{43}$ Thus 37 studies identified in the original search contributed to the systematic review and 35 contributed to the meta-analyses: 22 randomised controlled trials ${ }^{44-65}$ and 11 cohort studies $^{66-76}$ in adults and one randomised controlled trial ${ }^{77}$ and one cohort study ${ }^{78}$ in children. Figure $1 \Downarrow$ shows the process of study selection.

Because of the sparseness of data in children, we reassessed the 17 potentially eligible abstracts in children with broader inclusion criteria including more than three weeks' duration and any controlled design. We excluded 11 abstracts and assessed six full text articles for eligibility. We excluded four: one was cross sectional, one did not report an outcome of interest, and two did not report original data. We included two additional studies: one randomised controlled trial of three weeks' duration and one non-randomised controlled trial. ${ }^{79} 80$ Therefore, we included four studies in children: two randomised and one non-randomised controlled trials and one cohort study.

Randomised controlled trials in adults were conducted in Australia, Chile, China, Germany, India, Italy, Jamaica, Japan, Kenya, the Netherlands, New Zealand, South Africa, the United Kingdom, and the United States. Study duration ranged from four weeks to 12 months. A total of 1606 participants were included, with individual study sizes ranging from 12 to 353 . The intervention in one study was dietary advice or education, as well as a tablet supplement. In two studies, the intervention was dietary advice or education alone. The intervention in the remaining 20 studies was the provision of potassium supplements. For study characteristics, see supplementary material (OSM2).

The 12 cohort studies in adults were conducted in Finland, Japan, the Netherlands, Scotland, Taiwan, and the United States; one study included participants from 40 countries. One study did not report variance estimates and was, therefore, not included in the meta-analysis. In the meta-analysis, a total of 127038 participants were included, with sample sizes ranging from 443 to 38726 in individual studies. All cohort studies divided the sample population on the basis of potassium intake at baseline and measured all cause mortality or incident, fatal, or non-fatal cardiovascular disease, stroke, or coronary heart disease over time.

In children, the three controlled trials were conducted in the United States and the one cohort study in the Netherlands. The two randomised trials included a total of 250 boys and girls aged 13-15 years. The non-randomised controlled trial included 76 adolescents aged 11-14 years. The cohort study measured 596 children 5-17 years of age at baseline, and 253 were re-measured at the seven year follow-up.

\section{Effect estimates}

\section{Blood pressure in adults}

Twenty one randomised controlled trials contributed 21 comparisons to the meta-analyses of resting blood pressure in adults. Increased potassium intake reduced systolic blood pressure by 5.93 (95\% confidence interval 1.70 to 10.15$) \mathrm{mm}$ $\mathrm{Hg}$ and diastolic blood pressure by 3.78 (1.43 to 6.13) $\mathrm{mm} \mathrm{Hg}$. Heterogeneity was present in both analyses: $\mathrm{I}^{2}=96 \%$ for the systolic blood pressure analysis and $\mathrm{I}^{2}=93 \%$ for the diastolic blood pressure analysis. We independently removed each study from the analyses to explore the effect on the heterogeneity. We were able to reduce the $\mathrm{I}^{2}$ to $65 \%$ in the systolic blood pressure analysis by removing one study, ${ }^{52}$ and we reduced $\mathrm{I}^{2}$ to $55 \%$ in the diastolic analysis by removing two studies. ${ }^{51}{ }^{52}$ Increased potassium intake reduced systolic blood pressure by 3.49 (1.82 to 5.15$) \mathrm{mm} \mathrm{Hg}$ (fig $2 \Downarrow$ ) and diastolic blood pressure by 1.96 (0.86 to 3.06$) \mathrm{mm} \mathrm{Hg}$ (fig $3 \Downarrow$ ).

Table $1 \Downarrow$ contains results from subgroup analyses. Subgrouping by baseline hypertension status explained most of the remaining heterogeneity (figures $2 \Downarrow$ and $3 \Downarrow$ ). Increased potassium intake significantly reduced systolic and diastolic blood pressure in the 16 studies targeting people with hypertension (systolic blood pressure 5.32 (3.43 to 7.20 ) $\mathrm{mm} \mathrm{Hg}$; diastolic 3.10 (1.66 to 4.53) $\mathrm{mm} \mathrm{Hg}$ ) but not the three studies targeting people without hypertension (systolic 0.09 ( -0.77 to 0.95$) \mathrm{mm} \mathrm{Hg}$; diastolic (0.56 ( -0.42 to 1.55$) \mathrm{mm} \mathrm{Hg}$ ). When we sub-grouped studies by achieved potassium intake, we found that when the increased potassium group consumed $90-120 \mathrm{mmol} / \mathrm{day}$, the reduction in systolic (7.16 (1.91 to 12.41) $\mathrm{mm} \mathrm{Hg}$ ) and diastolic (4.01 (-0.42 to 8.44$) \mathrm{mm} \mathrm{Hg}$ ) blood pressure was larger than in any other intake group, although the groups were not statistically different from one another and no clear dose response was apparent.

Our other subgroup analyses showed that increased potassium intake decreased systolic blood pressure regardless of baseline potassium intake, blood pressure measurement device, blood pressure measurement method, the population status of use of drugs to control blood pressure, the intervention type, or the study design. When we sub-grouped studies according to the reported population sodium intake, the greatest decrease in systolic blood pressure (6.91 (2.29 to 11.53 ) $\mathrm{mm} \mathrm{Hg}$ ) was seen in the group of studies with the highest sodium consumption ( $>4 \mathrm{~g}$ sodium/day); however, this decrease was not significantly greater than the decrease in the group of studies in which the population consumed 2-4 g sodium/day (1.97 (0.52 to 3.41) mm $\mathrm{Hg}$ ). Increased potassium intake decreased systolic blood pressure in studies of a duration of less than two months (3.36 (1.78 to 4.94$) \mathrm{mm} \mathrm{Hg}$,) or 2-4 months (3.83 (0.95 to 6.72) mm $\mathrm{Hg}$ ). Only three studies had a duration of more than four months, ${ }^{44} 4648$ two of which were in people without hypertension, ${ }^{446}$ and increased potassium did not significantly reduce blood pressure in this group of studies $(-0.02(-0.90$ to $0.85) \mathrm{mm} \mathrm{Hg}$ ). Reductions in diastolic blood pressure in the subgroup analyses were less pronounced but similar to those of systolic blood pressure. 


\section{All cause mortality and disease endpoints in adults}

The meta-analysis of nine cohort studies with nine comparisons detected a protective effect of higher potassium intake on risk of incident stroke (risk ratio $0.76,0.66$ to 0.89 ). The risk of incident stroke was the least when the intake of potassium in the comparison group was $90-120 \mathrm{mmol} /$ day (risk ratio 0.70 , 0.56 to 0.88 ), although it was not significantly different from the result when the potassium intake was $<90 \mathrm{mmol} /$ day $(0.82$, 0.71 to 0.93 ). Potassium intake had a non-significant relation with incident cardiovascular disease (risk ratio $0.88,0.70$ to $1.10)$ and coronary heart disease $(0.96,0.78$ to 1.19$)$ (fig $4 \Downarrow$ ). Two cohort studies reported all cause mortality; however, the results could not be combined in a meta-analysis because one study did not report an estimate of variance. ${ }^{42}$ That study reported a relative risk of death of 0.58 for the 80 th centile versus the 20th centile of potassium intake, but statistical significance was not reported. The second study had inconclusive results (risk ratio $1.08,0.91$ to 1.29 ) when calculating the risk for every increase of one in standard deviation (45 mmol/day) in intake of potassium.

\section{Potential adverse effects in adults}

Meta-analyses of randomised controlled trials reporting changes in blood lipids showed no significant adverse effect of increased potassium on total cholesterol (mean difference $-0.12(-0.33$ to 0.09$) \mathrm{mmol} / \mathrm{L})$, low density lipoprotein cholesterol $(-0.10$ ( -0.38 to 0.18$) \mathrm{mmol} / \mathrm{L})$, high density lipoprotein cholesterol $(-0.01(-0.13$ to 0.11$) \mathrm{mmol} / \mathrm{L})$, or triglyceride concentrations $(-0.11(-0.48$ to 0.26$) \mathrm{mmol} / \mathrm{L})$ (fig $5 \Downarrow$ ). No studies measured urinary catecholamine concentrations. The meta-analyses of three randomised controlled trials reporting plasma catecholamine concentrations detected no effect of increased potassium intake on plasma adrenaline $(-3.94$ ( -9.22 to 1.34$)$ $\mathrm{pg} / \mathrm{mL})$ or plasma noradrenaline $(-4.32(-23.78$ to 15.13$)$ $\mathrm{pg} / \mathrm{mL}$ ). Three studies measured renal function by serum creatinine, and the meta-analysis showed that increased potassium intake decreased serum creatinine by a non-significant 4.86 ( -3.87 to 13.59$) \mu \mathrm{mol} / \mathrm{L}$. No studies reported minor side effects or other potential adverse effects from increased potassium intake.

\section{Blood pressure and potential adverse effects in children}

In the meta-analyses of the three randomised controlled trials with five comparisons in children, increased potassium intake decreased systolic blood pressure by a non-significant 0.28 ( -0.49 to 1.05 ) $\mathrm{mm} \mathrm{Hg}$ (fig $6 \Downarrow$ ) and diastolic blood pressure by $0.92(-0.16$ to 2.00$) \mathrm{mm} \mathrm{Hg}$. In the cohort study, potassium intake was inversely related to the rate of increase in blood pressure over a seven year period; the highest third of potassium intake had a $1.00(0.35$ to 1.65$) \mathrm{mm} \mathrm{Hg}$ per year lower increase in blood pressure than the lowest third. ${ }^{78}$ No studies that met the inclusion criteria reported the effect of increased potassium intake on blood lipid concentrations, catecholamine concentrations or other adverse effects in children.

\section{Quality of body of evidence}

The funnel plots of the set of studies in adults do not confirm small study bias; however, they also do not provide clear evidence of no small study bias in the set of studies in adults, so some small study bias may exist (see supplementary materials OSM3). In children, the number of studies was insufficient to generate meaningful funnel plots. The summary and graph of the assessment of other risk of bias (OSM4 and OSM5) suggest that the entire body of evidence in adults was not at high risk of bias. One randomised controlled trial in adults was at high risk of bias ${ }^{61}$; however, only five studies reported the method of random sequence generation and allocation concealment. ${ }^{4657586164}$ The body of evidence in children was at high risk of bias. Of the four studies, one was a cohort study, ${ }^{78}$ and one was not randomised. ${ }^{80}$ Only one study reported blinding of personnel and participants, ${ }^{77}$ and two studies did not blind personnel and participants. ${ }^{790}$ In all studies in children, whether the outcome assessors were blinded was unclear. ${ }^{77-80}$

According to the assessment of quality of evidence by GRADE methods,$^{30}$ the evidence for increased potassium reducing blood pressure in adults was of high or moderate quality (table $2 \Downarrow$ ). The evidence of no effect of increased potassium on blood lipid concentrations, catecholamine concentrations, or renal function was of high quality. The quality of evidence was not downgraded for any reason. The direct evidence for a protective effect of higher potassium intake on incident stroke was low because cohort studies began on the GRADE ranking as low quality and it was not downgraded for any reason. The quality of the direct evidence for an effect of potassium intake level on incident cardiovascular disease and coronary heart disease was very low. In both cases, the quality of evidence began as low because of the cohort study design and was downgraded owing to imprecision (that is, the $95 \%$ confidence interval of the effect estimate crossed one). The low and very low quality of this evidence reflects that the GRADE method defines observational evidence from cohort studies as low quality. Recognising the limitations of any biomarker, we considered data on change in systolic blood pressure as indirect evidence regarding the effect of sodium intake on risk of cardiovascular disease, stroke, and coronary heart disease. Blood pressure is recognised as a reliable biomarker for estimating risk of cardiovascular disease, ${ }^{81} 82$ because of the well established relation between increasing blood pressure and increasing risk of cardiovascular diseases, especially coronary heart disease and stroke. ${ }^{43}$ We downgraded the data owing to indirectness (that is, use of a proxy indicator). According to the GRADE assessment, ${ }^{30}$ the quality of evidence in children showing that increased potassium intake reduces systolic and diastolic blood pressure was low (table $3 \Downarrow$ ). We downgraded the controlled trials because of a high risk of bias as described previously and imprecision (95\% confidence interval of effect estimate crossed zero). We did not downgrade the cohort study for any reason but assessed it as low quality because of the study design, as per GRADE guidance. We used the data from the systematic review conducted in adults as part of the evidence base for estimating the effect of increased potassium on blood pressure and potential adverse effects in children and downgraded it from high to moderate in quality because of indirectness (that is, use of a proxy population for the target population).

We considered the entirety of the evidence and the quality of the body of evidence in adults and children in generating conclusions.

\section{Sensitivity analysis}

In the meta-analysis of randomised controlled trials in adults, we removed the one study at high risk of bias. ${ }^{61}$ Increased potassium intake still reduced systolic (3.50 (1.82 to 5.15$) \mathrm{mm}$ $\mathrm{Hg}$ ) and diastolic (2.95 (1.06 to 4.84) $\mathrm{mm} \mathrm{Hg}$ ) blood pressure. We removed cohort studies from the meta-analyses that measured exposure to potassium intake through one 24 hour dietary recall. ${ }^{70}$ Increased potassium was still associated with 
having a protective effect on risk of stroke (risk ratio $0.79,0.66$ to 0.95 ) and had no association with risk of incident coronary heart disease $(0.89,0.53$ to 1.48$)$. We removed the study that did not have random treatment allocation from the meta-analyses in children, ${ }^{80}$ and we saw little effect on the reduction in blood pressure $(0.27$ ( -0.62 to $1.15 \mathrm{~mm} \mathrm{Hg})$.

\section{Discussion}

The results from our meta-analyses of 22 randomised controlled trials in adults confirm that increased potassium intake reduces systolic and diastolic blood pressure. Our review is the first to document through a systematic search of the literature and meta-analyses that increased potassium has no adverse effect on blood lipid concentrations, catecholamine concentrations, or renal function in adults. We found a beneficial effect of higher potassium intake on risk of incident stroke but not of total cardiovascular disease or coronary heart disease; however, because few studies have reported these outcomes, detecting an effect is difficult even through meta-analysis.

\section{Benefits of increased potassium}

Our results on blood pressure are consistent with three previous meta-analyses, and a fourth systematic review without meta-analysis, of trials comparing higher potassium with lower potassium intake. ${ }^{20-23}$ One previous meta-analysis restricted to studies conducted in people with hypertension reported no effect of potassium supplementation on blood pressure. ${ }^{24}$ The discrepancy in results could be due to that review having included only six studies and 483 participants, whereas our review included 22 studies and 1892 participants, providing much more power to detect an effect. The meta-analyses of 11 cohort studies in adults suggest an association between higher potassium intake and reduced risk of stroke. These results are consistent with the previous meta-analysis of cohort studies, which reported that a $42 \mathrm{mmol} /$ day higher potassium intake was associated with a $21 \%$ lower risk of stroke. ${ }^{19}$

Our review was also the first in children and found a non-significant reduction in blood pressure. Importantly, we showed through a systematic search of the literature the lack of data in children. Only three controlled studies with 156 children met the inclusion criteria for the meta-analysis, so the lack of significant effect may reflect lack of statistical power. The suggestion of a beneficial effect in the controlled trials was supported by the one cohort study in children, which also reported a beneficial effect of higher potassium intake on blood pressure. Because renal function, and thus the body's main mechanism for controlling potassium balance, is fully developed early in childhood, potassium intake might be expected to have the same relation with blood pressure and the other health outcomes explored in children as in adults. Therefore, findings in adults can provide some support for an effect of increased potassium intake on blood pressure in children. Nevertheless, high quality randomised controlled trials in children are warranted to explore this relation further.

The meta analysis of 16 randomised controlled trials in adults with hypertension and in the two randomised controlled trials conducted in a mixed group of people with and without hypertension found that increased potassium intake decreased systolic blood pressure. However, potassium had no detectable effect on blood pressure in the meta-analysis of three randomised controlled trials conducted exclusively in people without hypertension. However, the studies in people without hypertension were of relatively short duration and did not consider the effect that increased potassium intake may have over time on the prevention of elevated blood pressure. Given the high prevalence of hypertension in adult populations, ${ }^{2}$ and the relatively low potassium intake globally, ${ }^{9485}$ populations around the world will probably benefit from increased potassium intake. Elevated blood pressure is the leading risk factor for mortality globally, accounting for almost $13 \%$ of deaths. ${ }^{3}$ The decrease in blood pressure caused by increased potassium intake can have important public health benefits at the population level. For example a decrease of $2 \mathrm{~mm} \mathrm{Hg}$ in diastolic blood pressure in the population of the United States could prevent an estimated 67000 coronary heart disease events and 34000 stroke events every year. ${ }^{86}$ Researchers estimate that a $5 \mathrm{~mm} \mathrm{Hg}$ reduction in systolic blood pressure in the population of the United Kingdom could reduce the prevalence of hypertension by $50 \%$ in that country. ${ }^{87}$

Through subgroup analysis, we attempted to assess if the type of intervention (supplements versus dietary changes) affected the relation between increased potassium intake and the outcomes of interest. Increasing potassium intake through dietary supplements and through dietary changes both reduced systolic blood pressure, suggesting that the vehicle of increased potassium intake can be food and does not have to be a supplement. The results from the cohort studies support this claim, as all cohort studies considered groups of varying dietary potassium intake and showed a beneficial effect of higher potassium intake from food on risk of stroke. Moreover, potassium is found in a wide variety of foods, so people can achieve a higher potassium intake through increasing consumption of foods such as fresh fruits and vegetables and pulses (legumes).

\section{Potential adverse effects}

We systematically searched for, compiled, and meta-analysed all available data on the potential adverse effect of increased potassium intake on blood lipid concentrations, catecholamine concentrations, and renal function and found that increased potassium, either in supplement or dietary form, had no adverse effects on these outcomes. Other researchers have shown that in people without renal impairment caused by medical conditions or drug treatment, increasing potassium consumption from food is safe. ${ }^{1748}{ }^{88-90}$ People with impaired urinary potassium excretion can be at risk of hyperkalaemia, an unhealthy elevated serum potassium concentration, from increased potassium consumption. ${ }^{17}$ The risk is confined to those patients, most of whom are under medical supervision, ${ }^{17}$ and they were not included in this review. In people without renal impairment, the body is able to efficiently adapt and excrete excess potassium in the urine when consumption exceeds needs. ${ }^{70}$ Intervention trials including potassium consumption as high as $400 \mathrm{mmol} /$ day from food for several weeks and $115 \mathrm{mmol} /$ day for up to a year reported no adverse effects from increased potassium intake. ${ }^{48} 90$ Some isolated cases of acute toxicity from extremely high potassium intake in supplement form have been reported, ${ }^{91}$ but no cases of toxicity from potassium intake from food have been reported. Because of the safety of consumption of increased potassium from food, our objectives did not include testing a potential upper limit of intake. We did, however, systematically search for and record any adverse effects reported by study authors. No studies reported increased side effects, minor complaints, or major adverse effects in the increased potassium groups compared with the control groups.

\section{Optimum potassium intake}

This review is the first to attempt to determine an optimum level of potassium intake for affecting health outcomes. Moderate 
and high quality evidence showed that a higher potassium intake of $90-120 \mathrm{mmol} /$ day reduced blood pressure and was associated with a lower risk of incident stroke. Intake above $120 \mathrm{mmol} / \mathrm{day}$ did not seem to have any additional benefit. However, the evidence from the randomised controlled trials and cohort studies in adults was limited in that it did not identify a precise optimal level of potassium intake for maximum health benefits. However, if a person consumes $90 \mathrm{mmol} /$ day or more potassium and the WHO recommended sodium intake of less than $2 \mathrm{~g} / \mathrm{day},{ }^{92}$ his or her intake would have a molar ratio of sodium to potassium of approximately one to one, a ratio considered beneficial for health. ${ }^{1031}$ A subgroup analysis of the randomised controlled trials to explore whether different levels of sodium intake influenced the effect of potassium on blood pressure showed no statistically significant difference in the effect estimates among subgroups based on sodium intake. However, the results suggest that potassium may be more effective in reducing blood pressure at higher levels of sodium consumption, consistent with previous findings. ${ }^{22}$ The largest benefit was detected when sodium intake was more than $4 \mathrm{~g} /$ day, which is the intake of most populations globally, ${ }^{93}$ so increased potassium intake should benefit most people in most countries. However, we also found a statistically significant decrease in blood pressure with increased potassium when sodium intake was 2-4 $\mathrm{g} / \mathrm{day}$. Therefore, increased potassium can continue to be beneficial in terms of blood pressure even as individuals and populations decrease their sodium intake. Studies examining both nutrients simultaneously support this concept, showing an increased benefit with simultaneous reduction in sodium and increase in potassium compared with changes in one nutrient individually. ${ }^{94} 95$

\section{Limitations of study}

Some limitations of this review should be noted. The funnel plots used to assess small study bias were not clear, and some small study bias may be present. Baseline hypertension status accounted for most heterogeneity in the analyses, and the consistency in results after subgrouping by hypertension status suggests that any such bias did not greatly affect the results or conclusions. This review did not cover the recommended period of exclusive breast feeding (0-6 months) or the period of complementary feeding with continued breastfeeding (6-24 months). The review did not include studies in patients with acute disease conditions such as HIV positive status, heart failure, or renal failure. Therefore, the results should not be interpreted to include those age groups or acutely ill patients, especially those with impaired renal function and defective renal potassium handling. We could not test whether the effect of increased potassium on health differed by the type of potassium provided in supplements. In supplementation studies, only one study used potassium citrate, one used potassium bicarbonate, and one used a combination of the two. All others used potassium chloride supplements. Therefore, we could not compare different supplement types. We could not compare differences by sex, because 20/22 randomised controlled trials and $9 / 12$ cohort studies were in mixed populations of men and women. None the less, the overall beneficial effect of increased potassium on health supports a beneficial effect in both men and women. Finally, we did not consider the mechanism by which increased potassium may affect blood pressure and related non-communicable disease.

\section{Conclusion}

This systematic review provides the most complete picture to date of epidemiological and clinical trial evidence in humans of the effect of potassium intake on blood pressure and related non-communicable diseases in apparently healthy adults and children without renal impairment that might compromise handling of potassium. It combines the data from 22 randomised controlled trials and 11 cohort studies in adults in meta-analyses and compiles and compares the data from four controlled trials and cohort studies in children. High quality evidence (based on GRADE criteria) from studies in adults shows that increased potassium intake benefits blood pressure without having an adverse effect on blood lipid concentrations, catecholamine concentrations, or renal function. Although data from studies conducted in children are limited, the available evidence suggests that increased potassium intake might reduce blood pressure, and consuming more potassium through foods high in potassium would probably be beneficial for most children. Low quality evidence (based on GRADE criteria) from cohort observational studies in adults shows that increased potassium intake has an inverse association with risk of incident stroke. Our results also suggest that the most benefit may occur when people consume at least $90 \mathrm{mmol}$ of potassium a day.

On the basis of the entirety of this evidence and informed by the expert guidance of the WHO Nutrition Guidelines Expert Advisory Group, WHO developed its first guideline on potassium intake, ${ }^{96}$ which states that adults and children without compromised renal handling of potassium should increase their potassium intake from food and that adults should consume more than $90 \mathrm{mmol}$ potassium/day for beneficial effects on blood pressure and risk of related cardiovascular diseases.

We gratefully acknowledge the support of funding bodies (see below), along with the countless hours provided by WHO Nutrition Guidance Expert Advisory Group members in providing input and comments on the document. We are also thankful to all stakeholders who provided their feedback on scoping the review.

Contributors: The WHO Nutrition Guidelines Expert Advisory Group Subgroup on Diet and Health discussed and developed the priority questions to be covered by the review in March 2011, and subsequently developed the protocol to answer those questions. NJA, HG, and SH ran the searches. $\mathrm{HG}$ and $\mathrm{SH}$ carried out the assessment of inclusion, data extraction, and validity assessment, with input from NJA. HG and NJA did the data analyses. NJA developed the first GRADE evidence profiles. NJA prepared the first draft of the report submitted for review by the WHO Nutrition Guidelines Expert Advisory Group Subgroup on Diet and Health, with support from HG and SH. The WHO Nutrition Guidelines Expert Advisory Group Subgroup on Diet and Health reviewed earlier drafts and contributed to the analysis and GRADE assessment. NJA wrote the first draft of the manuscript. LH, PE, and FPC provided substantial intellectual input on research methods and interpretation of results. All authors read, provided input on, and agreed the final draft of the manuscript. WHO agreed with the publication of this systematic review in a scientific journal as it serves as the background evidence review for establishing the WHO guideline on potassium intake for adults and for children and should, therefore, be widely available. NJA is the guarantor.

Funding: Funding for this review came from various sources, including WHO funds, the Kidney Evaluation Association Japan, and the governments of Japan and the Republic of Korea. PE receives support from the National Institute for Health Research (NIHR) Biomedical Research Centre based at Imperial College Healthcare NHS Trust and Imperial College London. PE is an NIHR Senior Investigator. The views expressed are those of the authors and not necessarily those of the NHS, the NIHR or the Department of Health.

Competing interests: All authors have completed the Unified Competing Interest form at www.icmje.org/coi_disclosure.pdf (available on request from the corresponding author) and declare: $\mathrm{LH}, \mathrm{FPC}$, and PE received 


\section{What is already known on this topic}

Lower potassium consumption has been associated with elevated blood pressure, hypertension, and stroke, and higher consumption levels could be protective against these conditions

The evidence regarding the potential beneficial effect of increased potassium intake on blood pressure and cardiovascular disease is not entirely consistent

Data regarding potential adverse effects on blood lipid concentrations, catecholamine concentrations, and renal function in adults and data in children are limited

\section{What this study adds}

This systematic review and meta-analyses provide the most comprehensive synthesis to date of the large body of evidence that increasing potassium intake reduces blood pressure in adults and that an inverse relation exists between potassium intake and incident stroke Increased potassium intake has no adverse effect on blood lipid concentration, catecholamine concentrations, or renal function in apparently healthy adults without impaired renal handling of potassium

Increased potassium intake may have a beneficial effect on blood pressure in children, but more data are needed

funding from WHO to attend NUGAG Subgroup of Diet and Health meetings; $\mathrm{PE}$ receives support from the National Institute for Health Research (NIHR) Biomedical Research Centre based at Imperial College Healthcare NHS Trust and Imperial College London; FPC is an unpaid member of Consensus Action on Salt and Health and World Action on Salt and Health, an unpaid advisor to WHO and the PAHO, an individual member of the National Heart Forum, and a former member of the Executive Committee and trustee of the British Hypertension Society; $\mathrm{PE}$ is an unpaid member of $\mathrm{CASH}$ and WASH and an unpaid advisor to WHO; no further financial support from any organisation for the submitted work that might have an interest in the submitted work in the previous three years; no other relationships or activities that could appear to have influenced the submitted work. NJA was a staff member of the $\mathrm{WHO}$ at the time this work was completed; the author alone is responsible for the views expressed in this publication, and they do not necessarily represent the views, decisions, or policies of WHO.

\section{Ethical approval: Not needed.}

Data sharing: The datasets are available from the corresponding author at nancy.aburto@wfp.org.

World Health Organization. Global status report on noncommunicable diseases. WHO 2010:164

2 World Health Organization. World health statistics 2012. WHO, 2012:176.

3 World Health Organization. Global health risks: mortality and burden of disease attributable to selected major risks. WHO, 2009:62 (www.who.int/healthinfo/global_burden disease/ GlobalHealthRisks_report_full.pdf).

4 Mackay J, Mensah G. Atlas of heart disease and stroke. WHO, 2004

5 Murray CJL, Lauer JA, Hutubessy RCW, Niessen L, Tomijima N, Rodgers A, et al. Effectiveness and costs of interventions to lower systolic blood pressure and cholesterol: a global and regional analysis on reduction of cardiovascular-disease risk. Lancet 2003:361:717-25

6 Chen X, Wang Y. Tracking of blood pressure from childhood to adulthood: a systematic review and meta-regression analysis. Circulation 2008;117:3171-80.

7 Young DB. Role of potassium in preventive cardiovascular medicine. Kluwer Academic Publishers, 2001

8 Cordain L, Eaton SB, Sebastian A, Mann N, Lindeberg S, Watkins BA, et al. Origins and evolution of the Western diet: health implications for the 21st century. Am J Clin Nutr 2005:81:341-54.

9 Intersalt Cooperative Research Group. Intersalt: an international study of electrolyte excretion and blood pressure. Results for 24 hour urinary sodium and potassium excretion. BMJ 1988;297:319-28.

10 World Health Organization. Diet, nutrition and the prevention of chronic disease: report of a Joint WHO/FAO Expert Consultation. WHO, 2003.

11 Federación Española de Sociedades de Nutrición, Alimentación y Dietética (FESNAD). Ingestas dietéticas de referencia (IDR) para la población Española. FESNAD, 2010.

12 Bourges H, Casanueva E, Rosado J. Recomendaciones de ingestión de nutrimentos para la población Mexicana. Bases fisiológicas. Vitaminas e nutrimentos inorgánicos. Editorial Medica Panamericana, 2004

13 Hoge Gezondheidsraad. Voedingsaanbevelingen voor België. Hoge Gezondheidsraad, 2009. (Herziening 2009, Dossiernummer 8309.)

14 Expert Group on Vitamins and Minerals. Revised review of potassium. 2002 (available at www.food.gov.uk/multimedia/pdfs/potassium.pdf)

15 Ministry of Health and Welfare, Korean Nutrition Society, Korean Food and Drug Administration. Dietary reference intakes for Koreans, 1st revision. Korean Food and Drug Administration, 2010.

16 Ministry of Health. Ordinance No23 from 19 July 2005 for physiological normative requirement (DRI) for nutrition of the population. In: State Gazzete 63. 2005.

17 Institute of Medicine. Dietary reference intakes for water, potassium, sodium, chloride, and sulfate. National Academies Press, 2005.

18 Dyer AR, Elliott P, Shipley M. Urinary electrolyte excretion in 24 hours and blood pressure in the Intersalt study. II. Estimates of electrolyte blood pressure associations corrected for regression dilution bias. Am J Epidemiol 1994;139:940-51.
19 D'Elia L, Barba G, Cappuccio F, Strazzullo P. Potassium intake, stroke, and cardiovascular disease: a meta-analysis of prospective studies. J Am Coll Cardiol 2011;57:1210-9.

20 Cappuccio FP, MacGregor GA. Does potassium supplementation lower blood pressure? A meta-analysis of published trials. J Hypertens 1991;9:465-73.

21 Geleijnse JM, Kok FJ, Grobbee DE. Blood pressure response to changes in sodium and potassium intake: a meta-regression analysis of randomised trials. $J$ Hum Hypertens 2003;17:471-80.

22 Whelton PK, He J, Cutler JA, Brancati FL, Appel LJ, Follmann D, et al. Effects of oral potassium on blood pressure: meta-analysis of randomized controlled clinical trials. JAMA 1997;277:1624-32

23 Dietary Guidelines Advisory Committee. What is the relationship between dietary potassium intake and blood pressure in adults? (available at www.nutritionevidencelibrary.com/ evidence.cfm?evidence_summary_id=250306).

24 Dickinson HO, Nicolson DJ, Campbell F, Beyer FR, Mason J. Potassium supplementation for the management of primary hypertension in adults. Cochrane Database Syst Rev 2006;3:CD004641.

25 Higgins JPT, Green S, eds. Cochrane handbook for systematic reviews of interventions, version 5.1.0. Cochrane Collaboration, 2011.

26 Liberati A, Altman DG, Tetzlaff J, Mulrow C, Gøtzsche PC, loannidis JP, et al. The PRISMA statement for reporting systematic reviews and meta-analyses of studies that evaluate healthcare interventions: explanation and elaboration. BMJ 2009;339:b2700.

27 Deeks JJ, Dinnes J, D'Amico R, Sowden AJ, Sakarovitch C, Song F, et al. Evaluating non-randomised intervention studies. Health Technol Assess 2003;7:1-173.

28 Lau J, loannidis JP, Terrin N, Schmid CH, Olkin I. The case of the misleading funnel plot. BMJ 2006;333:597-600

29 Sterne JA, Egger M. Funnel plots for detecting bias in meta-analysis: guidelines on choice of axis. Clin Epidemiol 2001;54:1046-55.

30 Guyatt GH, Oxman AD, Vist GE, Kunz R, Falck-Ytter Y, Alonso-Coello P, et al. GRADE: an emerging consensus on rating quality of evidence and strength of recommendations. BMJ 2008:336:924-6.

31 Stamler J, P Elliott P, Chan Q, for the INTERMAP Research Group. Intermap appendix tables. J Hum Hyper 2003;17:665-758.

32 Higgins JP, Thompson SG, Spiegelhalter DJ. A re-evaluation of random-effects meta-analysis. J R Stat Soc Ser A Stat Soc 2009;172:137-59.

33 Higgins J, Thompson S, Deeks J, Altman D. Statistical heterogeneity in systematic reviews of clinical trials: a critical appraisal of guidelines and practice. $J$ Health Serv Res Policy 2002:7:51-61.

34 Higgins JP, Thompson SG. Quantifying heterogeneity in a meta-analysis. Stat Med 2002;21:1539-58.

35 Barros MA, Brito IM. Potassium in essential arterial hypertension. CCS (Universidade Federal da Paraiba, Centro de Ciências da Saúde) 1984:6:48-55.

36 Morris R, O'Connor M, Forman A, Peeks R, Sebastian A. Supplemental dietary potassium with $\mathrm{KHCO} 3$ but not $\mathrm{KCl}$ attenuates essential hypertension [abstract]. J Am Soc Nephrol 1995:6:645.

37 Kawano Y, Minami J, Takishita S. Effects of potassium, calcium and magnesium supplementation in patients with essential hypertension-assessment by blood pressure monitoring. Therapeutic Research 1997;18:44-7.

38 limura O, Kijima T, Kikuchi K, Miyama A, Ando T, Nakao T, et al. Studies on the hypotensive effect of high potassium intake in patients with essential hypertension. Clin Sci 1981:61:77-80S.

39 Hilary Green J, Richards JK, Bunning RL. Blood pressure responses to high-calcium skim milk and potassium-enriched high-calcium skim milk. $J$ Hypertens 2000;18:1331-9.

40 Cushman WC, Langford HG. Randomized controlled trial of potassium chloride versus placebo in mildly hypertensive blacks and whites. Circulation 1988;17:S370

41 Braschi A, Naismith DJ. The effect of a dietary supplement of potassium chloride or potassium citrate on blood pressure in predominantly normotensive volunteers. $\mathrm{Br} J$ Nutr 2008;99:1284-92.

42 Tunstall-Pedoe H, Woodward M, Tavendale R, Brook R, McCluskey MK. Comparison of the prediction by 27 different factors of coronary heart disease and death in men and women of the Scottish Heart Health Study: cohort study. BMJ 1997;315:722-9.

43 Overlack A, Conrad H, Stumpe KO. The influence of oral potassium citrate/ bicarbonate on blood pressure in essential hypertension during unrestricted salt intake. Klin Wochenschr 1991;69:S79-83.

44 Whelton PK, Kumanyika SK, Cook NR, Cutler JA, Borhani NO, Hennekens CH, et al. The effect of potassium supplementation in persons with a high-normal blood pressure: results from phase I of the Trials of Hypertension Prevention. Am J Clin Nutr 1995:65:S652-60.

45 Valdés G, Vio CP, Montero J, Montero J, Avendaño R. Potassium supplementation lowers blood pressure and increases urinary kallikrein in essential hypertensives. $J$ Hum Hypertens 1991;5:91-6.

46 The effects of nonpharmacologic interventions on blood pressure of persons with high normal levels: results of the Trials of Hypertension Prevention, phase I. JAMA 1992;267:1213-20. 
47 Smith SJ, Markandu ND, Sagnella GA, MacGregor GA. Moderate potassium chloride supplementation in essential hypertension: is it additive to moderate sodium restriction? BMJ 1985:290:110-3

48 Siani A, Strazzullo P, Giacco A, Pacioni D, Celentano E, Mancini M. Increasing the dietary potassium intake reduces the need for antihypertensive medication. Ann Intern Med 1991;115:753-59.

49 Siani A, Strazzullo P, Russo L, Guglielmi S, lacoviello L, Ferrara LA, et al. Controlled trial of long term oral potassium supplements in patients with mild hypertension. $B M J$ 1987;294:1453-6.

50 Richards AM, Nicholls MG, Espiner EA, Ikram H, Maslowski AH, Hamilton EJ, et al. Blood pressure response to moderate sodium restriction and to potassium supplementation in mild essential hypertension. Lancet 1984;1:757-61.

51 Patki PS, Singh J, Gokhale SV, Bulakh PM, Shrotri DS, Patwardhan B. Efficacy of potassium and magnesium in essential hypertension: a double blind, placebo controlled, crossover study. BMJ 1990;301:521-3.

52 Obel AO. Placebo-controlled trial of potassium supplements in black patients with mild essential hypertension. J Cardiovasc Pharmacol 1989;42:294-6.

53 Matlou SM, Isles CG, Higgs A, Milne FJ, Murray GD, Schultz E, et al. Potassium supplementation in blacks with mild to moderate essential hypertension. $J$ Hypertens 1986;4:61-4.

54 MacGregor GA, Smith SJ, Markandu ND, Banks RA, Sagnella GA. Moderate potassium supplementation in essential hypertension. Lancet 1982;11:567-70.

55 Kawano Y, Minami J, Takishita S, Omae T. Effects of potassium supplementation on office, home and 24-hour blood pressure in patients with essential hypertension. Am J Hypertens 1998;11:1141-6.

56 Kaplan NM, Carnegie A, Raskin P, Heller JA, Simmons M. Potassium supplementation in hypertensive patients with diuretic-induced hypokalemia. N Engl J Med 1985;312:746-9.

57 He FJ, Marciniak M, Carney C, Markandu ND, Anand V, Fraser WD, et al. Effects of potassium chloride and potassium bicarbonate on endothelial function, cardiovascula risk factors, and bone turnover in mild hypertensives. Hypertension 2010;55:681-8.

58 Gu D, He J, Wu X, Duan X, Whelton PK. Effect of potassium supplementation on blood pressure in Chinese: a randomized, placebo-controlled trial. J Hypertens 2001;19:1325-31.

59 Grobbee DE, Hofman A, Roelandt JT, Boosma F, Schalekamp MA, Valkenburg HA. Sodium restriction and potassium supplementation in young people with mildly elevated blood pressure. J Hypertens 1987;5:115-9.

60 Fotherby MD, Potter JF. Potassium supplementation reduces clinic and ambulatory blood pressure in elderly hypertensive patients. J Hypertens 1992;10:1403-8.

61 Forrester TE, Grell GA. Changes in red cell sodium content and blood pressure levels with potassium supplementation in black hypertensive patients. West Indian Med 1988;37:92-6.

62 Chalmers J, Morgan T, Doyle A, Dickson B, Hopper J, Mathews J, et al. Australian National Health and Medical Research Council dietary salt study in mild hypertension. $J$ Hypertens 1986;4:S629-37.

63 Bulpitt CJ, Ferrier G, Lewis PJ, Daymond M, Bulpitt PF, Dollery CT. Potassium supplementation fails to lower blood pressure in hypertensive patients receiving a potassium losing diuretic. Ann Clin Res 1985;17:126-30.

64 Berry SE, Mulla UZ, Chowienczyk PJ, Sanders TA. Increased potassium intake from fruit and vegetables or supplements does not lower blood pressure or improve vascular function in UK men and women with early hypertension: a randomised controlled trial. $\mathrm{Br} J \mathrm{Nutr}$ 2010;104:1839-47.

65 Barden A, Vandongen R, Beilin LJ. Increases in urinary kallikrein activity and prostanoid synthesis after dietary potassium supplementation. Clin Exp Pharmacol Physiol 1987;14:565-72

66 Weng LC, Yeh WT, Bai CH, Chen HJ, Chuang SY, Chang HY, et al. Is ischemic stroke risk related to folate status or other nutrients correlated with folate intake? Stroke 2008;39:3152-8

67 Umesawa $\mathrm{M}$, Iso $\mathrm{H}$, Date $\mathrm{C}$, Yamamoto $\mathrm{A}$, Toyoshima $\mathrm{H}$, Watanabe $\mathrm{Y}$, et al. Relations between dietary sodium and potassium intakes and mortality from cardiovascular disease: the Japan Collaborative Cohort Study for Evaluation of Cancer Risks. Am J Clin Nutr 2008;88:192-202.

68 O'Donnell MJ, Yusuf S, Mente A, Gao P, Mann JF, Teo K, et al. Urinary sodium and potassium excretion and risk of cardiovascular events. JAMA 2011;306:2229-37.

69 Larsson SC, Virtanen MJ, Mars M, Männistö S, Pietinen P, Albanes D, et al. Magnesium, calcium, potassium, and sodium intakes and risk of stroke in male smokers. Arch Intern Med 2008:168:459-65.

70 Khaw KT, Barrett-Connor E. Dietary potassium and stroke-associated mortality: a 12-yea prospective population study. N Engl J Med 1987;316:235-40

71 Iso H, Stampfer MJ, Manson JE, Rexrode K, Hennekens $\mathrm{CH}$, Colditz GA, et al. Prospective study of calcium, potassium, and magnesium intake and risk of stroke in women. Stroke 1999;30:1772-9.
72 Green DM, Ropper AH, Kronmal RA Psaty BM, Burke GL. Serum potassium level and dietary potassium intake as risk factors for stroke. Neurology 2002;59:314-20.

73 Geleijnse JM, Witteman JC, Stijnen T, Kloos MW, Hofman A, Grobbee DE. Sodium and potassium intake and risk of cardiovascular events and all-cause mortality: the Rotterdam Study. Eur J Epidemiol 2007;22:763-70.

74 Cook NR, Obarzanek E, Cutler JA, Buring JE, Rexrode KM, Kumanyika SK, et al, for the Trials of Hypertension Prevention Collaborative Research Group. Joint effects of sodium and potassium intake on subsequent cardiovascular disease: the trials of hypertension prevention (TOHP) follow-up study. Arch Intern Med 2009;169:32-40

75 Bazzano LA, He J, Ogden LG, Loria C, Vupputuri S, Myers L, et al. Dietary potassium intake and risk of stroke in US men and women: National Health and Nutrition Examination Survey I epidemiologic follow-up study. Stroke 2001;32:1473-80.

76 Ascherio A, Rimm EB, Hernán MA, Giovannucci EL, Kawachi I, Stampfer MJ, et al. Intake of potassium, magnesium, calcium, and fiber and risk of stroke among US men. Circulation 1998:98:1198-204

77 Sinaiko AR, Gomez-Marin O, Prineas RJ. Effect of low sodium diet or potassium supplementation on adolescent blood pressure. Hypertension 1993;21:989-94.

78 Geleijnse JM, Grobbee DE, Hofman A. Sodium and potassium intake and blood pressure change in childhood. BMJ 1990;300:899-902.

79 Wilson DK, Sica DA, Devens M, Nicholson SC. The influence of potassium intake on dipper and nondipper blood pressure status in an African-American adolescent population. Blood Press Monit 1996;1:447-55.

80 Miller JZ, Weinberger MH, Christian JC. Blood pressure response to potassium supplementation in normotensive adults and children. Hypertension 1987;10:437-42.

81 Vasan RS. Biomarkers of cardiovascular disease: molecular basis and practical considerations. Circulation 2006:113:2335-62.

82 Desai M, Stockbridge N, Temple R. Blood pressure as an example of a biomarker that functions as a surrogate. AAPS J 2006;8:E146-52.

83 Lewington S, Clarke R, Qizilbash N, Peto R, Collins R, for the Prospective Studies Collaboration. Age-specific relevance of usual blood pressure to vascular mortality: a meta-analysis of individual data for one million adults in 61 prospective studies. Lancet 2002;360:1903-13.

84 Energy and nutrient intake in the European Union. Ann Nutr Metab 2004:48(suppl 2):1-16

85 Van Mierlo LAJ, Greyling A, Zock PL, Kok FJ, Geleijnse JM. Suboptimal potassium intake and potential impact on population blood pressure. Arch Intern Med 2010;170:1501-2.

86 Cook NR, Cohen J, Hebert PR, Taylor JO, Hennekens $\mathrm{CH}$. Implications of small reduction in diastolic blood pressure for primary prevention. Arch Intern Med 1995:155:701-9.

87 McPherson K, Britton A, Causer L. Coronary heart disease: estimating the impact of changes in risk factors. National Heart Forum, 2002.

88 Saggar-Malik AK, Cappuccio FP. Potassium supplements and potassium-sparing diuretics: a review and guide to appropriate use. Drugs 1993;46:986-1008.

89 Hathcock JN. Potassium. In: Vitamin and mineral safety. 2nd ed. Council for Responsible Nutrition, 2004.

90 Rabelink TJ, Koomans HA, Hene RJ, Dorhout Mees EJ. Early and late adjustment to potassium loading in humans. Kidney Int 1990:38:942-7.

91 EFSA Panel on Dietetic Products, Nutrition and Allergies. Opinion of the Scientific Panel on Dietetic Products, Nutrition and Allergies (NDA) related to the tolerable upper intake level of sodium (Request EFSA-Q-2003-018). European Food Safety Authority Journal 2005;193:1-19.

92 World Health Organization. Guideline: sodium intake for adults and children. WHO, 2012.

93 Brown IJ, Tzoulaki I, Candeias V, Elliott P. Salt intakes around the world: implications for public health. Int J Epidemiol 2009;38:791-813.

94 Kawasaki T, Itoh K, Kawasaki M. Reduction in blood pressure with a sodium-reduced, potassium- and magnesium-enriched mineral salt in subjects with mild essential hypertension. Hypertens Res 1998;21:235-43.

95 Chang HY, Hu YW, Yue CS, Wen YW, Yeh WT, Hsu LS, et al. Effect of potassium-enriched salt on cardiovascular mortality and medical expenses of elderly men. Am J Clin Nutr 2006;83:1289-96.

96 World Health Organization. Guideline: potassium intake for adults and children. WHO 2012.

Accepted: 18 February 2013

\section{Cite this as: BMJ 2013:346:f1378}

This is an Open Access article distributed in accordance with the Creative Commons Attribution Non Commercial (CC BY-NC 3.0) license, which permits others to distribute, remix, adapt, build upon this work non-commercially, and license their derivative works on different terms, provided the original work is properly cited and the use is non-commercial. See: http://creativecommons.org/licenses/by-nc/3.0/. 


\section{Tables}

\section{Table 1 | Estimates of effect of increased potassium on systolic and diastolic blood pressure in adults by subgroups}

\begin{tabular}{|c|c|c|c|c|c|c|c|c|}
\hline \multirow{2}{*}{ Subgroup* } & \multicolumn{4}{|c|}{ Systolic blood pressure } & \multicolumn{4}{|c|}{ Diastolic blood pressure } \\
\hline & Studies & No & $I^{2}$ & Effect estimate-MD (95\% & Studies & No & $\beth^{2}$ & Effect estimate-MD (95\% \\
\hline Overall & 21 & 1892 & 65 & $-3.49(-5.15$ to -1.82$)$ & 21 & 1857 & 55 & $-1.96(-3.06$ to -0.86$)$ \\
\hline \multicolumn{9}{|l|}{$\begin{array}{l}\text { Blood pressure status at } \\
\text { baseline: }\end{array}$} \\
\hline Without hypertension & 3 & 757 & 0 & 0.09 (-0.77 to 0.95$)$ & 3 & 722 & 37 & $-0.56(-1.55$ to 0.42$)$ \\
\hline With hypertension & 16 & 818 & 21 & $-5.32(-7.20$ to -3.43$)$ & 15 & 828 & 24 & $-3.10(-4.53$ to -1.66$)$ \\
\hline \multicolumn{9}{|c|}{$\begin{array}{l}\text { Achieved potassium intake in } \\
\text { intervention groupt: }\end{array}$} \\
\hline$<90 \mathrm{mmol} / \mathrm{day}$ & 2 & 183 & 0 & $-3.65(-6.69$ to -0.62$)$ & 2 & 183 & 45 & $-1.35(-5.31$ to 2.60$)$ \\
\hline $90-120 \mathrm{mmol} / \mathrm{day}$ & 5 & 286 & 71 & $-7.16(-12.41$ to -1.91$)$ & 4 & 212 & 75 & $-4.01(-8.44$ to 0.42$)$ \\
\hline $120-155 \mathrm{mmol} / \mathrm{day}$ & 10 & 1187 & 53 & $-1.71(-3.42$ to -0.00$)$ & 9 & 1051 & 21 & $-0.83(-1.82$ to 0.17$)$ \\
\hline$>155 \mathrm{mmol} /$ day & 4 & 236 & 0 & $-3.00(-6.28$ to 0.27$)$ & 4 & 236 & 0 & $-1.75(-4.23$ to 0.74$)$ \\
\hline
\end{tabular}

Difference in achieved

potassium intake between

intervention and control:

\begin{tabular}{lcccccccc}
\hline$<30 \mathrm{mmol} / \mathrm{day}$ & 6 & 501 & 53 & $-4.89(-7.59$ to -2.20$)$ & 5 & 427 & 66 & $-1.87(-4.11$ to 0.37$)$ \\
\hline $30-60 \mathrm{mmol} / \mathrm{day}$ & 11 & 1169 & 51 & $-1.97(-3.85$ to -0.09$)$ & 11 & 1134 & 53 & $-1.63(-3.04$ to -0.21$)$ \\
\hline$>60 \mathrm{mmol} / \mathrm{day}$ & 4 & 222 & 26 & $-3.01(-7.03$ to 1.02$)$ & 4 & 222 & 0 & $-3.57(-6.32$ to -0.82$)$ \\
\hline
\end{tabular}

Average potassium intake at

baseline†:

\begin{tabular}{|c|c|c|c|c|c|c|c|c|}
\hline$<50 \mathrm{mmol} /$ day & 2 & 169 & 0 & $-3.89(-7.03$ to -0.74$)$ & 2 & 169 & 74 & $-2.41(-7.90$ to 3.07$)$ \\
\hline $50-80 \mathrm{mmol} / \mathrm{day}$ & 14 & 1372 & 70 & $-3.39(-5.51$ to -1.28$)$ & 13 & 1263 & 45 & $-1.53(-2.80$ to -0.25$)$ \\
\hline$>80 \mathrm{mmol} /$ day & 5 & 351 & 0 & $-4.11(-6.26$ to -1.97$)$ & 5 & 351 & 0 & $-3.38(-4.74$ to -2.02$)$ \\
\hline \multicolumn{9}{|c|}{ Sodium intake at baseline: } \\
\hline$<2 \mathrm{~g} /$ day & 1 & 40 & NA & $-2.00(-11.70$ to 7.70$)$ & 1 & 40 & NA & $0.00(-6.12$ to 6.12$)$ \\
\hline $2-4$ g/day & 15 & 1470 & 42 & $-1.97(-3.41$ to -0.52$)$ & 15 & 1435 & 54 & $-1.96(-3.16$ to -0.76$)$ \\
\hline$>4$ g/day & 5 & 382 & 71 & $-6.91(-11.53$ to -2.29$)$ & 4 & 308 & 74 & $-2.87(-6.96$ to 1.22$)$ \\
\hline \multicolumn{9}{|c|}{ Duration of intervention: } \\
\hline$<2$ months & 14 & 933 & 0 & $-3.36(-4.94$ to -1.78$)$ & 14 & 933 & 0 & $-1.99(-3.11$ to -0.87$)$ \\
\hline 2-4 months & 7 & 1074 & 85 & $-3.83(-6.72$ to -0.95$)$ & 6 & 965 & 82 & $-1.86(-3.75$ to 0.02$)$ \\
\hline$>4$ months & 3 & 718 & 0 & $0.02(-0.85$ to 0.90$)$ & 3 & 683 & 0 & $-0.35(-1.06$ to 0.35$)$ \\
\hline
\end{tabular}

Type of blood pressure device

used:

\begin{tabular}{lcccccccccc}
\hline Automatic & 10 & 608 & 0 & $-3.45(-5.13$ to -1.77$)$ & 10 & 608 & 0 & $-2.84(-3.96$ to -1.71$)$ \\
\hline Manual & 11 & 1284 & 76 & $-3.63(-5.98$ to -1.28$)$ & 10 & 1175 & 59 & $-1.54(-2.96$ to -0.11$)$ \\
\hline
\end{tabular}

Type of blood pressure

measurement method used:

\begin{tabular}{lccccccccc}
\hline Supine office & 13 & 692 & 52 & $-4.88(-7.64$ to -2.13$)$ & 13 & 692 & 85 & $-4.34(-7.57$ to -1.10$)$ \\
\hline Seated office & 7 & 1169 & 67 & $-1.83(-3.54$ to -0.12$)$ & 7 & 1134 & 69 & $-1.30(-2.64$ to 0.04$)$ \\
\hline Standing office & 8 & 351 & 38 & $-6.94(-10.63$ to -3.25$)$ & 8 & 351 & 83 & $-4.78(-9.38$ to -0.18$)$ \\
\hline Unspecified & 2 & 117 & 0 & $-2.51(-7.87$ to 2.85$)$ & 2 & 117 & 40 & $0.83(-4.45$ to 6.11$)$ \\
\hline
\end{tabular}

Use of antihypertensive drugs

at baseline:

\begin{tabular}{lcccccccccc}
\hline Not taking drugs & 13 & 1421 & 72 & $-3.63(-5.69$ to -1.57$)$ & 12 & 1312 & 51 & $-1.37(-2.50$ to -0.23$)$ \\
\hline Taking drugs & 5 & 195 & 34 & $-5.85(-10.61$ to -1.08$)$ & 5 & 195 & 66 & $-3.80(-8.25$ to 0.66$)$ \\
\hline Type of intervention: & & & & & & & & \\
\hline Supplement & 19 & 1744 & 63 & $-3.31(-5.07$ to -1.55$)$ & 19 & 1709 & 88 & $-3.04(-5.09$ to -0.99$)$ \\
\hline Dietary advice or education & 3 & 244 & 0 & $-4.19(-6.46$ to -1.92$)$ & 3 & 244 & 57 & $-2.44(-5.04$ to 0.17$)$ \\
\hline
\end{tabular}


Table 1 (continued)

\begin{tabular}{|c|c|c|c|c|c|c|c|c|}
\hline \multirow[b]{2}{*}{ Subgroup* } & \multicolumn{4}{|c|}{ Systolic blood pressure } & \multicolumn{4}{|c|}{ Diastolic blood pressure } \\
\hline & Studies & No & $I^{2}$ & $\begin{array}{c}\text { Effect estimate-MD (95\% } \\
\mathrm{Cl})\end{array}$ & Studies & No & $I^{2}$ & $\begin{array}{c}\text { Effect estimate-MD (95\% } \\
\mathrm{Cl})\end{array}$ \\
\hline \multicolumn{9}{|l|}{ Study design: } \\
\hline Parallel & 7 & 1026 & 78 & $-2.74(-5.08$ to -0.39$)$ & 7 & 991 & 80 & $-1.59(-3.35$ to 0.18$)$ \\
\hline Crossover & 14 & 866 & 32 & $-3.99(-6.13$ to -1.86$)$ & 15 & 903 & 84 & $-4.21(-7.12$ to -1.29$)$ \\
\hline
\end{tabular}

$\mathrm{NA}=$ not available.

*Mean difference (inverse variance, random effects model).

†Potassium intake was measured through 24 hour urinary potassium excretion and estimated from urinary excretion by using conversion factor of $1.3 .^{31}$ 
Table 2| GRADE summary of findings table showing quality of evidence for effect of higher potassium intake on selected health outcomes in adults

\begin{tabular}{|c|c|c|c|c|}
\hline Outcomes & Effect $(95 \% \mathrm{Cl})$ & $\begin{array}{l}\text { No of participants } \\
\text { (studies) }\end{array}$ & $\begin{array}{l}\text { Quality of evidence } \\
\text { (GRADE) }\end{array}$ & Comments \\
\hline $\begin{array}{l}\text { Resting systolic blood pressure* (follow-up } \\
1-36 \text { months; units } \mathrm{mm} \mathrm{Hg} \text {; better indicated } \\
\text { by lower values) }\end{array}$ & $\begin{array}{c}\text { MD } 3.49 \text { lower (5.15 to } 1.82 \\
\text { lower) }\end{array}$ & $1892(21)$ & High & None \\
\hline $\begin{array}{l}\text { Cardiovascular disease } \dagger \text { (directly } \\
\text { assessed; } R R<1 \text { indicates decreased risk } \\
\text { with increased potassium intake) }\end{array}$ & RR 0.88 (0.70 to 1.11$)$ & $29067(4)$ & Very low & $\begin{array}{l}\text { Data from cohort studies begin } \\
\text { with GRADE of low; downgraded } \\
\text { owing to imprecision }\end{array}$ \\
\hline $\begin{array}{l}\text { Cardiovascular disease } \ddagger \text { (assessed by } \\
\text { change in blood pressure }(\mathrm{mm} \mathrm{Hg}) \text {; better } \\
\text { indicated by lower values) }\end{array}$ & $\begin{array}{c}\text { MD } 3.49 \text { lower (5.15 to } 1.82 \\
\text { lower) }\end{array}$ & $1892(21)$ & Moderate & $\begin{array}{l}\text { Data downgraded owing to } \\
\text { indirectness }\end{array}$ \\
\hline $\begin{array}{l}\text { Stroke (directly assessed; } R R<1 \text { indicates } \\
\text { decreased risk with increased potassium } \\
\text { intake) }\end{array}$ & RR 0.79 (0.68 to 0.93 ) & $97152(9)$ & Low & $\begin{array}{l}\text { Data from cohort studies begin } \\
\text { with GRADE of low }\end{array}$ \\
\hline $\begin{array}{l}\text { Stroke } \neq \text { (assessed by change in blood } \\
\text { pressure (mm Hg); better indicated by } \\
\text { lower values) }\end{array}$ & $\begin{array}{c}\text { MD } 3.49 \text { lower (5.15 to } 1.82 \\
\text { lower) }\end{array}$ & $1892(21)$ & Moderate & $\begin{array}{l}\text { Data downgraded owing to } \\
\text { indirectness }\end{array}$ \\
\hline $\begin{array}{l}\text { Coronary heart disease (directly assessed; } \\
R R<1 \text { indicates decreased risk with } \\
\text { increased potassium intake) }\end{array}$ & RR 0.97 (0.77 to 1.24$)$ & $31162(3)$ & Very low & $\begin{array}{l}\text { Data from cohort studies begin } \\
\text { with GRADE of low; downgraded } \\
\text { owing to imprecision }\end{array}$ \\
\hline $\begin{array}{l}\text { Coronary heart disease } \neq \text { (assessed by } \\
\text { change in blood pressure }(\mathrm{mm} \mathrm{Hg}) \text {; better } \\
\text { indicated by lower values) }\end{array}$ & $\begin{array}{c}\text { MD } 3.49 \text { lower (5.15 to } 1.82 \\
\text { lower) }\end{array}$ & $1892(21)$ & Moderate & $\begin{array}{l}\text { Data downgraded owing to } \\
\text { indirectness }\end{array}$ \\
\hline $\begin{array}{l}\text { All cause mortality (directly assessed; } \\
R R<1 \text { indicates decreased risk with } \\
\text { increased potassium intake) }\end{array}$ & RR 1.08 (0.91 to 1.29$)$ & $1766(1)$ & Very low & $\begin{array}{l}\text { Only one study reported this } \\
\text { outcome; downgraded owing to } \\
\text { imprecision }\end{array}$ \\
\hline $\begin{array}{l}\text { Total cholesterol§ (follow-up 1-2 months; } \\
\text { units } \mathrm{mmol} / \mathrm{L} \text {; better indicated by lower } \\
\text { values) }\end{array}$ & $\begin{array}{c}\text { MD } 0.12 \text { lower ( } 0.33 \text { lower to } \\
0.09 \text { higher })\end{array}$ & $208(3)$ & High & - \\
\hline $\begin{array}{l}\text { Plasma noradrenaline } 9 \text { (follow-up 1-2.5 } \\
\text { months; units } \mathrm{pg} / \mathrm{mL} \text {; better indicated by } \\
\text { lower values) }\end{array}$ & $\begin{array}{c}\text { MD } 4.32 \text { lower (23.78 lower to } \\
15.13 \text { higher) }\end{array}$ & $152(3)$ & High & - \\
\hline $\begin{array}{l}\text { Serum creatinine (follow-up mean } 1.5 \\
\text { months; units } n g / \mathrm{mL} \text { filtrate; better indicated } \\
\text { by lower values) }\end{array}$ & $\begin{array}{l}\text { MD } 4.86 \text { lower (13.59 lower to } \\
3.87 \text { higher) }\end{array}$ & $147(3)$ & High & - \\
\hline $\begin{array}{l}\text { Minor side effects (better indicated by lower } \\
\text { values) }\end{array}$ & - & - & - & No studies reported this outcome \\
\hline
\end{tabular}

$\mathrm{MD}=$ mean difference; $\mathrm{RR}=$ risk ratio.

*Additional evidence from meta-analysis of 20 randomised controlled trials with 20 comparisons reporting resting diastolic blood pressure is supportive of benefit of increased potassium on blood pressure (MD $1.96 \mathrm{~mm} \mathrm{Hg}$ lower, 3.06 to 0.86 lower) (quality of evidence high); meta-analysis of 4 randomised controlled studies with 4 comparisons reporting ambulatory systolic blood pressure is supportive of benefit of increased potassium on blood pressure (MD $3.04 \mathrm{~mm}$ Hg lower, 5.42 to 0.66 lower) (quality of evidence moderate); meta-analysis of 4 randomised controlled trials with 4 comparisons reporting ambulatory diastolic blood pressure is consistent with benefit of increased potassium on blood pressure (MD $1.24 \mathrm{~mm} \mathrm{Hg}$ lower, 3.13 lower to 0.66 higher) (quality of evidence moderate).

†Composite cardiovascular disease as reported by original study authors. This variable included some or all of fatal and non-fatal stroke; coronary heart disease; myocardial infarction; congestive cardiac failure; or episode of coronary revascularisation, bypass grafting, or angioplasty.

$\ddagger$ Data from systolic blood pressure used as evidence for effect of potassium intake on risk of cardiovascular disease, stroke, and coronary heart because blood pressure is good proxy indicator for risk of these outcomes. ${ }^{45-47}$

§Additional evidence on relation between potassium intake and blood lipids comes from meta-analysis of 2 randomised controlled trials with 2 comparisons reporting high density lipoprotein cholesterol concentration supportive of no effect of increased potassium in blood lipids (MD $0.01 \mathrm{mmol} / \mathrm{L}$ lower, 0.13 lower to 0.11 higher) (quality of evidence high) and meta-analysis of 2 randomised controlled trials with 2 comparisons reporting triglyceride concentration supportive of no effect of increased potassium on blood lipids (MD $0.11 \mathrm{mmol} / \mathrm{L}$ lower, 0.48 lower to 0.26 higher) (quality of evidence high). Only one randomised controlled trial in literature reported low density lipoprotein concentration; it was consistent with no effect of increased potassium on blood lipids (MD $0.10 \mathrm{mmol} / \mathrm{L}$ lower, 0.38 lower to 0.18 higher).

TMeta-analysis of 3 randomised controlled trials with 3 comparisons reporting plasma adrenaline concentration is supportive of no effect of increased potassium on catecholamine concentrations (MD $3.94 \mathrm{pg} / \mathrm{mL}$ lower, 9.22 lower to 1.34 higher) (quality of evidence high). No studies reporting urinary catecholamine concentrations were found. 
Table 3| GRADE summary of findings table showing quality of evidence for effect of higher potassium intake on selected health outcomes in children

\begin{tabular}{|c|c|c|c|c|}
\hline Outcomes & $\begin{array}{c}\text { Effect } \\
(95 \% \mathrm{Cl})\end{array}$ & $\begin{array}{c}\text { No of participants } \\
\text { (studies) }\end{array}$ & $\begin{array}{l}\text { Quality of evidence } \\
\text { (GRADE) }\end{array}$ & Comments \\
\hline $\begin{array}{l}\text { Resting systolic blood pressure }{ }^{*} \text { (assessed directly } \\
\text { in children; follow-up } 0.75-1 \text { month; units } \mathrm{mm} \mathrm{Hg} \text {; } \\
\text { better indicated by lower values) }\end{array}$ & $\begin{array}{c}\text { MD } 0.28 \text { lower ( } 1.05 \text { lower } \\
\text { to } 0.49 \text { higher) }\end{array}$ & $236(3)$ & Low & $\begin{array}{c}1 \text { of } 3 \text { studies was not randomised; } \\
\text { downgraded owing to high risk of bias } \\
\text { and imprecision. }\end{array}$ \\
\hline $\begin{array}{l}\text { Resting systolic blood pressure } \text { (assessed in } \\
\text { adults; follow-up 1-36 months; units } \mathrm{mm} \mathrm{Hg} \text {; better } \\
\text { indicated by lower values) }\end{array}$ & $\begin{array}{c}\text { MD } 3.49 \text { lower ( } 5.15 \text { to } 1.82 \\
\text { lower) }\end{array}$ & $1892(21)$ & Moderate & Downgraded owing to indirectness \\
\hline Total cholesterol (assessed directly in children) & - & - & - & $\begin{array}{c}\text { No studies in children reported on this } \\
\text { outcome }\end{array}$ \\
\hline $\begin{array}{l}\text { Total cholesterol } \dagger \text { (assessed in adults; follow-up } \\
1-2 \text { months; units } \mathrm{mmol} / \mathrm{L} \text {; better indicated by lower } \\
\text { values) }\end{array}$ & $\begin{array}{c}\text { MD } 0.12 \text { lower ( } 0.33 \text { lower } \\
\text { to } 0.09 \text { higher) }\end{array}$ & $208(3)$ & Moderate & Downgraded owing to indirectness \\
\hline $\begin{array}{l}\text { Plasma noradrenaline (assessed directly in } \\
\text { children) }\end{array}$ & - & - & - & $\begin{array}{c}\text { No studies in children reported on this } \\
\text { outcome }\end{array}$ \\
\hline $\begin{array}{l}\text { Plasma noradrenalinet (assessed in adults; } \\
\text { follow-up } 1-2.5 \text { months; units } \mathrm{pg} / \mathrm{mL} \text {; better } \\
\text { indicated by lower values) }\end{array}$ & $\begin{array}{c}\text { MD } 4.32 \text { lower ( } 23.78 \text { lower } \\
\text { to } 15.13 \text { higher) }\end{array}$ & $152(3)$ & Moderate & Downgraded owing to indirectness \\
\hline Minor side effects (assessed directly in children) & - & - & - & $\begin{array}{l}\text { No studies in children reported on this } \\
\text { outcome }\end{array}$ \\
\hline Minor side effects (assessed in adults) & - & - & - & $\begin{array}{c}\text { No studies in adults reported on this } \\
\text { outcome }\end{array}$ \\
\hline
\end{tabular}

$\mathrm{MD}=$ mean difference.

*One observational cohort study in children is consistent with beneficial effect of increased potassium on blood pressure over time.

†Data from adults used as proxy for children. 


\section{Figures}

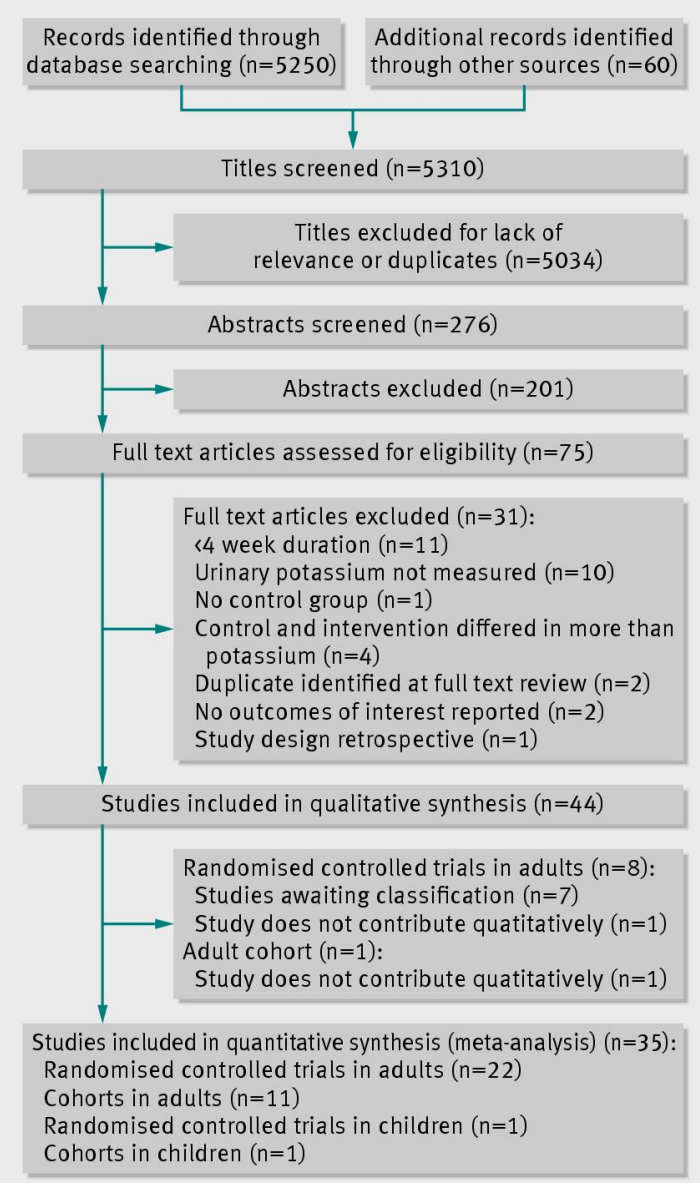

Fig 1 Flow of studies through screening, inclusion, and exclusion. RCT=randomised controlled trial 
Study

\section{Mean (SD)/Total No of participants}

Study

Increased Control

potassium intake

\section{Blood pressure status (normoten sive)}

Barden BPARA $1986 \quad 113.67(8.87) / 43 \quad 113.69(9.44) / 43$ Trial Hyp Prv Col BPA $1992-0.78(5.88) / 178 \quad-0.84(5.82) / 175$ Whelton BPA $1995 \quad-0.87(5.94) / 161 \quad-1.00(5.69) / 157$ Subtotal $382 \quad 375$

Test for heterogeneity: $\tau^{2}=0.00, \chi^{2}=0.01, d f=2, P=1.00, I^{2}=0 \%$

Test for overall effect: $z=0.20, P=0.84$

\section{Blood pressure status (hypertensive)}

Bulpitt BPA 1985

Chalmers BPA 1986

$-5.20(27.50) / 19$

$-8.90(7.00) / 49$

$7.50(23.90) / 14$

Forrester BPA 1988

Fotherby BPA 1992

Grobbee BPA 1987

He BPA 2010

Kaplan BPA 1985

Kawano BPA 1998

MacGregor AEBPA 1982

Matlou BPA 1986

Obel BPA 1989

Patki BPARA 1990

Richards BPAAEA 1984

Siani BPA 1987

Siani BPARA 1991

Smith BPARA 1985

Valdes BPA 1991

$133.20(12.70) / 2$

$176.00(20.00) / 18 \quad 186.00(24.00) / 18$

$135.00(13.28) / 40 \quad 135.90(11.38) / 40$ $142.00(11.00) / 42 \quad 145.00(15.00) / 42$ $127.60(11.60) / 16 \quad 133.20(16.80) / 16$ $147.90(11.70) / 55 \quad 150.80(12.61) / 55$ $148.00(13.91) / 23 \quad 155.00(14.87) / 23$ $144.00(18.10) / 32 \quad 151.00(19.20) / 32$ $133.00(10.00) / 24 \quad 172.00(7.00) / 24$ $143.60(10.80) / 37 \quad 155.70(11.40) / 37$ $148.00(14.20) / 12 \quad 149.90(14.50) / 12$ $131.80(12.70) / 18 \quad 145.80(11.30) / 19$ $142.10(11.50) / 21 \quad 145.50(9.70) / 26$ $160.00(16.10) / 20 \quad 162.00(15.20) / 20$ $138.00(14.70) / 24 \quad 145.00(9.80) / 24$ $449 \quad 453$

Subtotal

Test for heterogeneity: $\tau^{2}=2.89, \chi^{2}=19.06, \mathrm{df}=15, \mathrm{P}=0.21, \mathrm{I}^{2}=21 \%$ Test for overall effect: $z=2.15, P=0.03$

Blood pressure status (heterogeneous)

$\begin{array}{lcc}\text { Berry BPA 2010 } & 120.70(9.90) / 48 & 122.20(13.00) / 48 \\ \text { Gu BPA 2001 } & -13.10(10.70) / 68 & -9.40(9.00) / 69 \\ \text { Subtotal } & 116 & 117\end{array}$

Subtotal

Test for heterogeneity: $\tau^{2}=0.00, \chi^{2}=0.57, \mathrm{df}=1, \mathrm{P}=0.45, \mathrm{I}^{2}=0 \%$ Test for overall effect: $z=2.15, P=0.03$

Total $(95 \% \mathrm{Cl})$

947

945

Test for heterogeneity: $\tau^{2}=6.52, \chi^{2}=56.52, d f=20, P<0.001,\left.\right|^{2}=65 \%$

Test for overall effect: $z=4.10, P<0.001$

Test for subgroup differences: $\chi^{2}=28.26, \mathrm{df}=2, \mathrm{P}<0.001, \mathrm{I}^{2}=92.9 \%$

$2.9 \%$ potassium

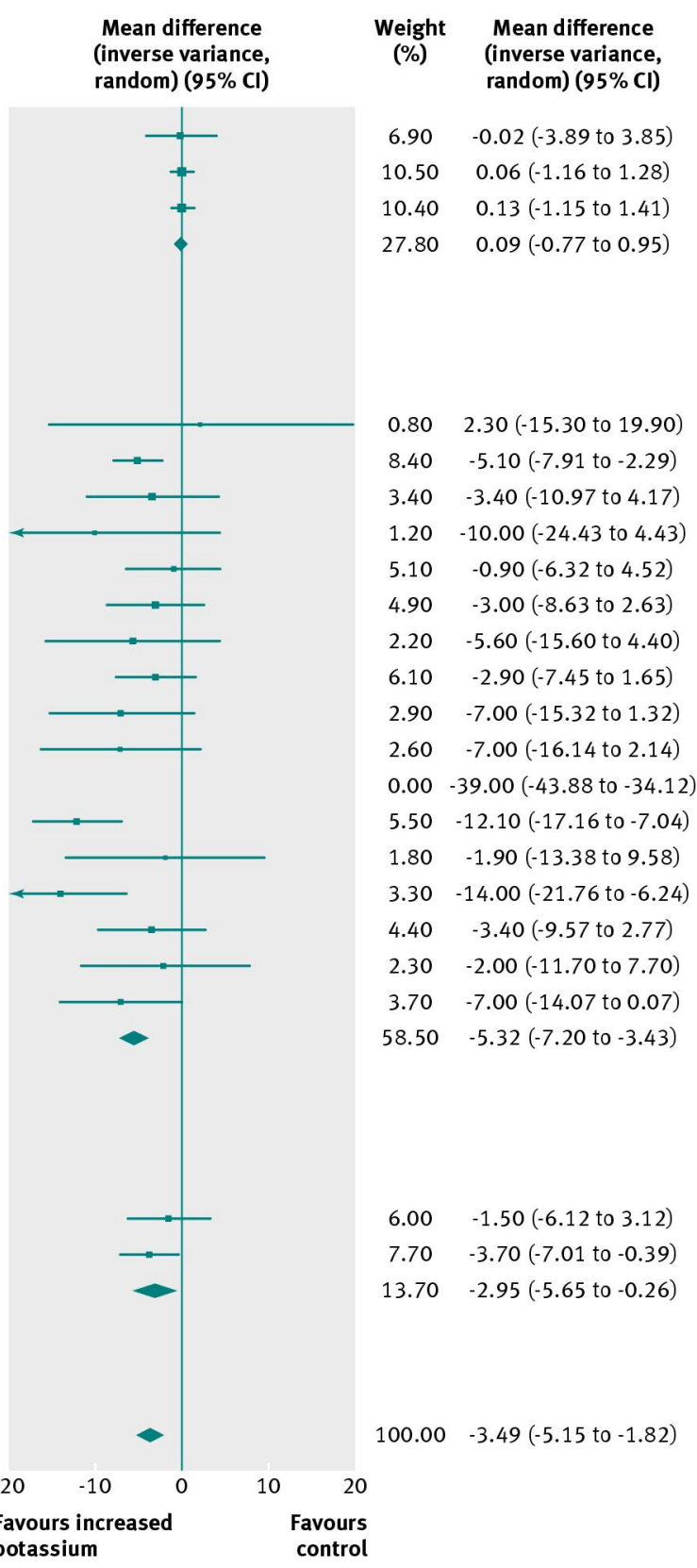

Weight Mean difference random) $(95 \% \mathrm{Cl})$

$6.90-0.02(-3.89$ to 3.85$)$

$10.50 \quad 0.06$ (-1.16 to 1.28$)$

$10.40 \quad 0.13(-1.15$ to 1.41$)$

$27.80 \quad 0.09(-0.77$ to 0.95$)$

$0.80 \quad 2.30(-15.30$ to 19.90$)$

$-5.10(-7.91$ to -2.29$)$

$5.10-0.90(-6.32$ to 4.52$)$

$4.90 \quad-3.00$ (-8.63 to 2.63$)$

$2.20 \quad-5.60(-15.60$ to 4.40$)$

$6.10-2.90(-7.45$ to 1.65$)$

$2.90-7.00(-15.32$ to 1.32$)$

$2.60 \quad-7.00(-16.14$ to 2.14$)$

$0.00-39.00(-43.88$ to -34.12$)$

$5.50-12.10(-17.16$ to -7.04$)$

$1.80-1.90(-13.38$ to 9.58$)$

$3.30-14.00(-21.76$ to -6.24$)$

$4.40 \quad-3.40(-9.57$ to 2.77$)$

$2.30-2.00(-11.70$ to 7.70$)$

$3.70-7.00(-14.07$ to 0.07$)$

$58.50-5.32(-7.20$ to -3.43$)$

$6.00-1.50(-6.12$ to 3.12$)$

$7.70-3.70(-7.01$ to -0.39$)$

$13.70-2.95(-5.65$ to -0.26$)$ 


\section{Mean (SD)/Total No of participants}

Study

Increased $\quad$ Control
potassium intake

\section{Blood pressure status (normotensive)}

$\begin{array}{lcc}\text { Barden BPARA 1986 } & 68.02(7.24) / 43 & 71.67(9.68) / 43 \\ \text { Trial Hyp Prv Col BPA 1992 } & -0.27(4.56) / 161 & 0.14(4.64) / 157 \\ \text { Whelton BPA 1995 } & -0.29(4.68) / 161 & -0.03(4.5) / 157 \\ \text { Subtotal } & 365 & 357\end{array}$

Test for heterogeneity: $\tau^{2}=0.28, \chi^{2}=3.15, \mathrm{df}=2, \mathrm{P}=0.21, \mathrm{I}^{2}=37 \%$

Test for overall effect: $z=1.12, P=0.26$

\section{Blood pressure status (hypertensive)}

Bulpitt BPA 1985

Chalmers BPA 1986

Forrester BPA 1988

Fotherby BPA 1992

Grobbee BPA 1987

He BPA 2010

Kaplan BPA 1985

Kawano BPA 1998

MacGregor AEBPA 1982

Matlou BPA 1986

Obel BPA 1989

Patki BPARA 1990

Richards BPAAEA 1984

Siani BPA 1987

Siani BPARA 1991

Smith BPARA 1985

Valdes BPA 1991

$0.50(11.80) / 19$

$-5.80(4.20) / 49$

$87.70(12.10) / 23$

$94.00(20.00) / 18$

$71.60(10.75) / 40$

$90.00(9.00) / 42$

$91.90(7.60) / 16$

$86.80(8.16) / 55$

$95.00(7.67) / 23$

$144.00(18.10) / 32$

$83.00(4.00) / 24$

$84.50(3.50) / 37$

$91.40(11.40) / 12$

$82.00(8.90) / 18$

$83.10(9.20) / 21$

$103.00(8.94) / 20$

$89.00(9.80) / 24$

412

$-4.30(11.20) / 14$

$-1.60(4.50) / 52$

$92.30(9.20) / 23$

$100.00(14.00) / 18$

$73.70(9.49) / 40$

$91.00(9.00) / 42$

$97.70(7.60) / 16$

$88.10(9.64) / 55$

$99.00(8.15) / 23$

$151.00(19.20) / 32$

$100.00(4.00) / 24$

$97.60(5.40) / 37$

$92.40(12.10) / 12$

$92.50(8.70) / 19$

$84.20(6.60) / 26$

$103.00(10.73) / 20$

$92.00(9.80) / 24$ 416

Test for heterogeneity: $\tau^{2}=1.739, \chi^{2}=18.50, \mathrm{df}=14, \mathrm{P}=0.18, \mathrm{I}^{2}=24 \%$

Test for overall effect: $z=4.24, P<0.001$

Blood pressure status (heterogeneous)

$\begin{array}{lcc}\text { Berry BPA 2010 } & 76.60(6.54) / 48 & 76.90(7.50) / 48 \\ \text { Gu BPA 2001 } & -3.80(6.20) / 68 & -3.70(6.00) / 69 \\ \text { Subtotal } & 116 & 117\end{array}$

Subtotal

$2^{2}=0.01, d f=1, P=0.91,\left.\right|^{2}=0 \%$

Test for overall effect: $z=0.20, P=0.84$

Total $(95 \% \mathrm{Cl})$

893

890

Test for heterogeneity: $\tau^{2}=2.31, \chi^{2}=41.97, \mathrm{df}=19, \mathrm{P}=0.002, \mathrm{I}^{2}=55 \%$

Test for overall effect: $z=3.49, P<0.001$

Test for subgroup differences: $\chi^{2}=9.81, \mathrm{df}=2, \mathrm{P}=0.007, \mathrm{I}^{2}=79.6 \% \quad \begin{aligned} & \text { Favours } \\ & \text { high potassium }\end{aligned}$

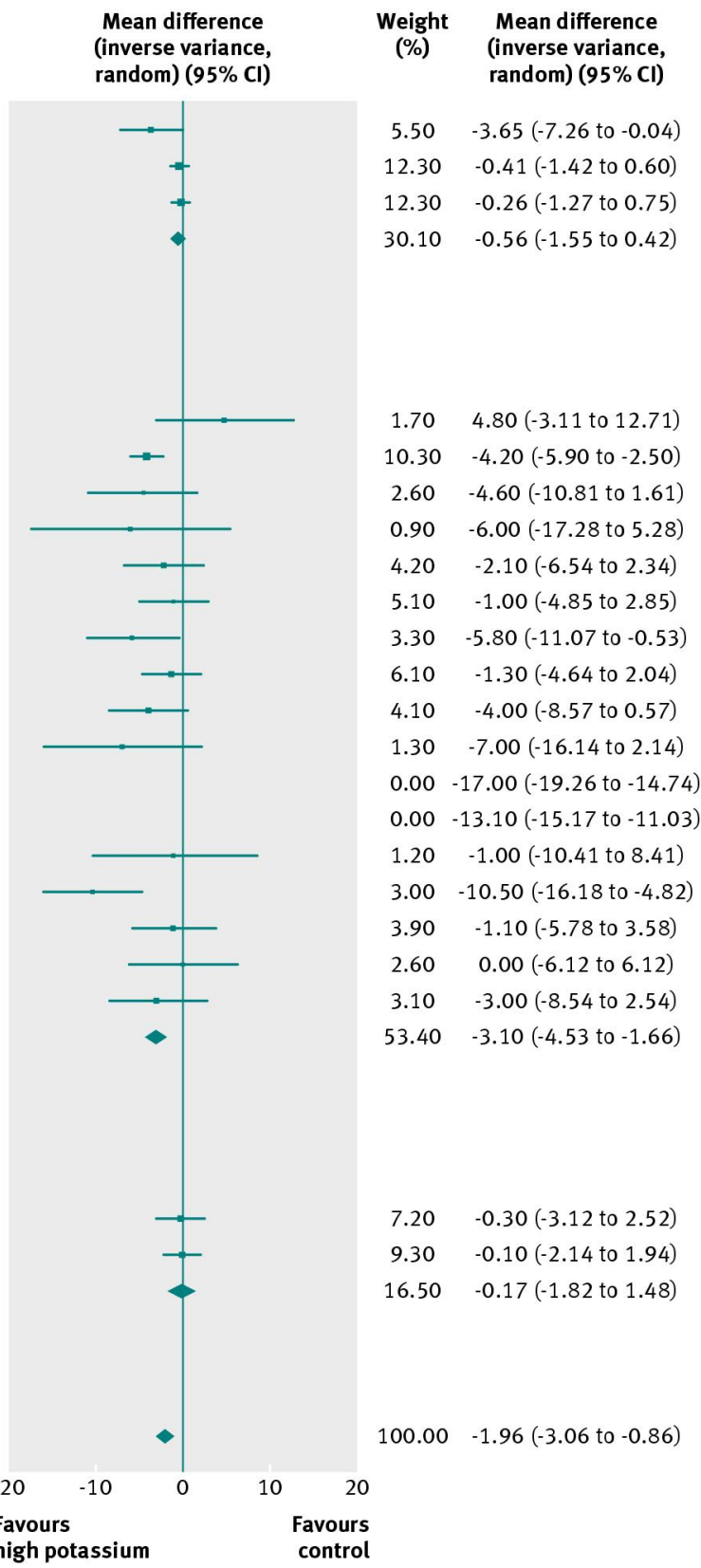

Fig 3 Effect of increased potassium intake on resting diastolic blood pressure in adults: by hypertension status and total 


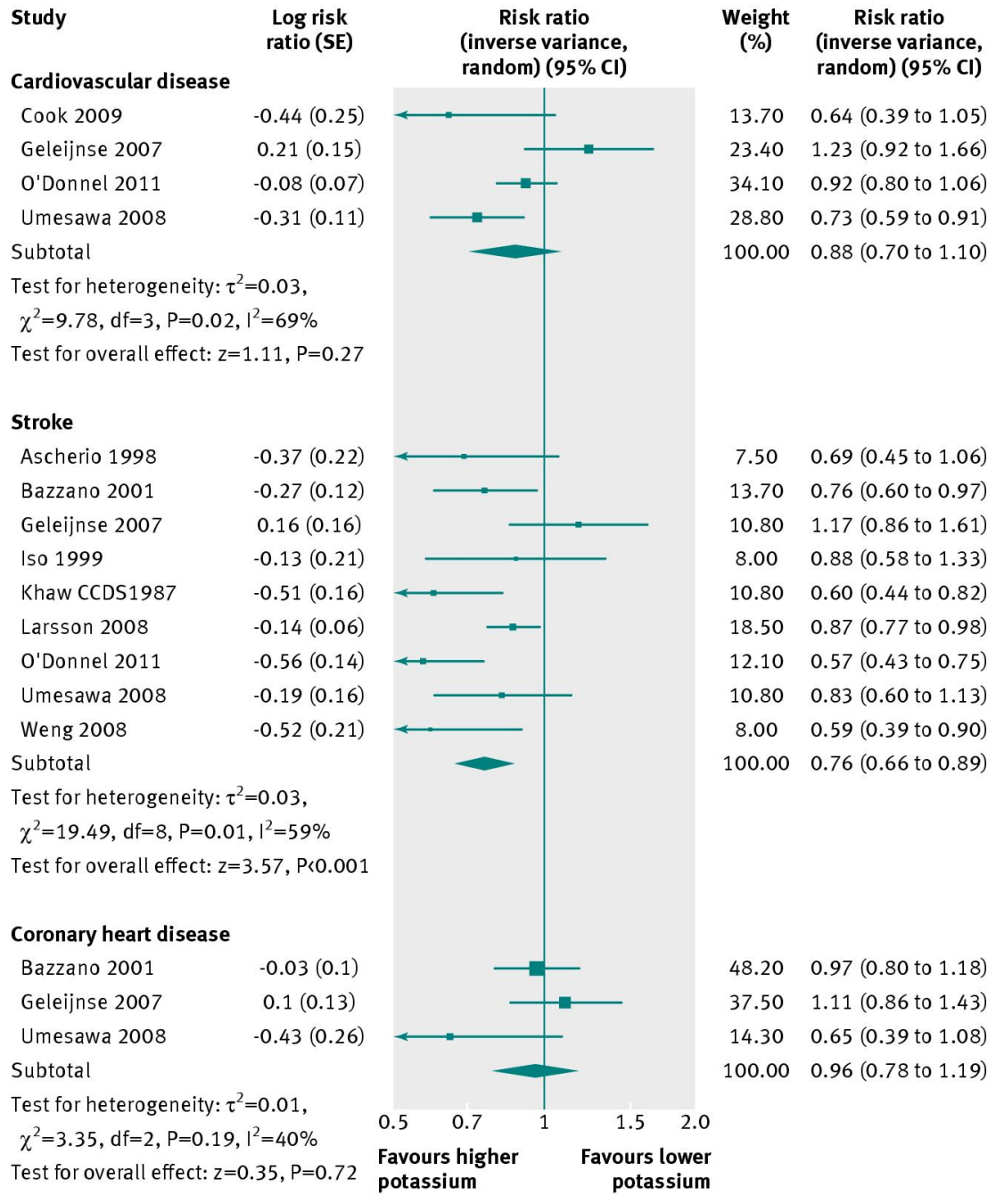

Fig 4 Association between higher potassium intake and risk of incident cardiovascular disease, stroke, and coronary heart disease in adults 


\section{Study}

\section{Total cholesterol}

Berry BPA 2010

Grobbee BPA 1987

Kaplan BPA 1985

Patki BPARA 1990

Subtotal

Test for heterogeneity: $\tau^{2}=0.00, \chi^{2}=0.63, \mathrm{df}=2, \mathrm{P}=0.73, \mathrm{I}^{2}=0 \%$

Test for overall effect: $z=1.14, P=0.25$

\section{Low density lipoprotein cholestero}

$\begin{array}{ccc}\text { Berry BPA } 2010 & 3.70(0.71) / 48 & 3.80(0.71) / 48 \\ \text { Subtotal } & 48 & 48\end{array}$

Test for heterogeneity: not applicable

Test for overall effect: $z=0.69, P=0.49$

\section{High density liporotein cholesterol}

$\begin{array}{lll}\text { Berry BPA 2010 } & 1.40(0.35) / 48 & 1.40(0.35) / 48 \\ \text { Kaplan BPA 1985 } & 1.16(0.37) / 16 & 1.21(0.39) / 16\end{array}$

Subtotal

64

64

Test for heterogeneity: $\tau^{2}=0.00, \chi^{2}=0.11, \mathrm{df}=1, \mathrm{P}=0.74, \mathrm{I}^{2}=0 \%$

Test for overall effect: $\mathrm{z}=0.17, \mathrm{P}=0.86$

\section{Triglycerides}

\section{Berry BPA 2010}

Kaplan BPA 1985

Subtotal

$1.10(0.53) / 48$

$1.64(1.34) / 16$

$1.30(0.53) / 48$

$1.36(0.84) / 16$

$$
64
$$

64

Test for heterogeneity: $\tau^{2}=0.03, \chi^{2}=1.37, \mathrm{df}=1, \mathrm{P}=0.24, \mathrm{I}^{2}=27 \%$

Test for overall effect: $z=0.59, P=0.55$

\section{Adrenaline (plasma)}

Grobbee BPA 1987

Richards BPAAEA 1984

$67.00(44.27) / 40$

$73.00(7.00) / 12$

$77.00(56.92) / 40$

Valdes BPA 1991

$42.00(39.19) / 24$

$77.00(7.00) / 12$

Subtotal

$$
76
$$

$39.00(39.19) / 24$

Test for heterogeneity: $\tau^{2}=0.00, \chi^{2}=0.66, d f=2, P=0.72, I^{2}=0 \%$

Test for overall effect: $z=1.46, P=0.14$

\section{Noradrenaline (plasma)}

\section{Grobbee BPA 1987}

Richards BPAAEA 1984

Valdes BPA 1991

$225.00(132.82) / 40239.00(120.17) / 40$ $404.00(28.00) / 12 \quad 405.00(28.00) / 12$ $203.00(97.98) / 24 \quad 218.00(97.98) / 24$

$$
\text { Subtotal }
$$$$
76
$$
76

Test for heterogeneity: $\tau^{2}=0.00, \chi^{2}=0.34, \mathrm{df}=2, \mathrm{P}=0.84, \mathrm{I}^{2}=0 \%$

Test for overall effect: $z=0.44, P=0.66$

\section{Creatinine (serum)}

Bulpitt BPA 1985

Patki BPARA 1990

$84.00(18.70) / 19$

$73.38(6.96) / 37$

$110.00(39.2) / 14$

Smith BPARA 1985

Subtotal

$91.00(14.31) / 20$

Test for heterogeneity: $\tau^{2}=31.33, \chi^{2}=4.39, \mathrm{df}=2, \mathrm{P}=0.11, \mathrm{I}^{2}=54 \%$

Test for overall effect: $z=1.09, P=0.28$

Fig 5 Effect of increased potassium intake on blood lipid concentrations, catecholamine concentrations, and renal function in adults

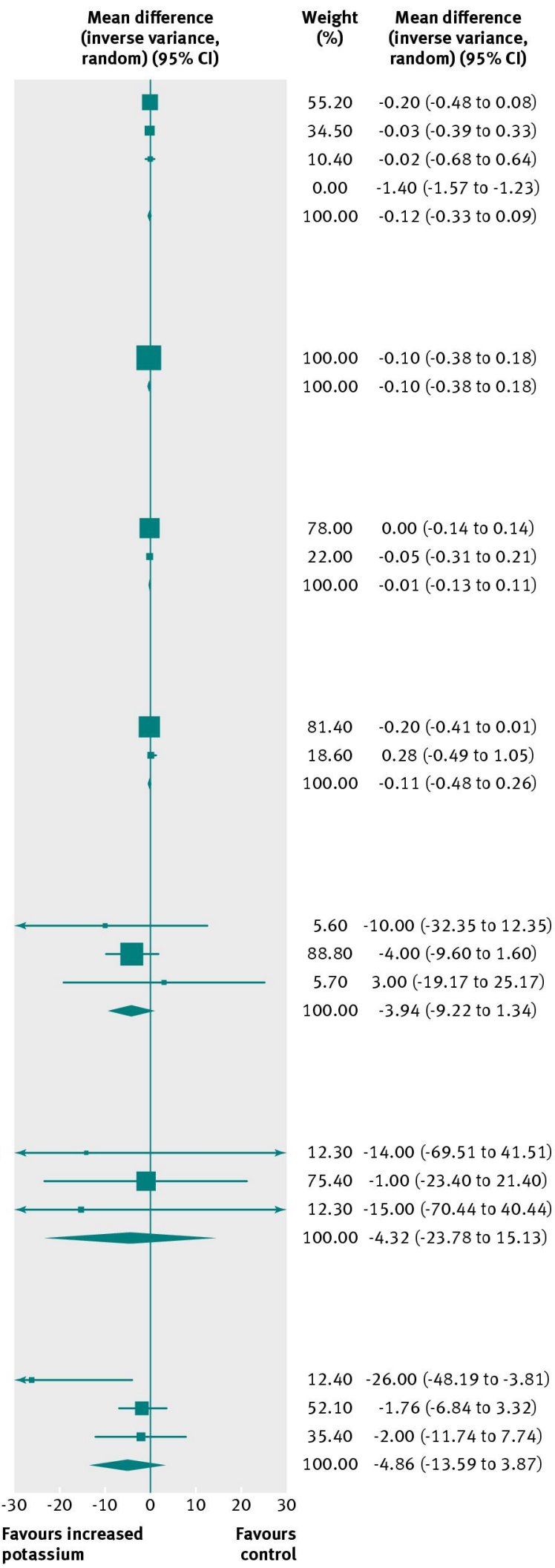


Study

\begin{tabular}{|c|c|}
\hline $\begin{array}{c}\text { Increased } \\
\text { potassium intake }\end{array}$ & Control \\
\hline
\end{tabular}

Miller 1987

Sinaiko $1993 \mathrm{M}$

Sinaiko $1993 \mathrm{M}$

Wilson 1996

Wilson 1996

Total

Test for heterogeneity: $\tau^{2}=0.00, \chi^{2}=3.34, d f=4, P=0.50, I^{2}=0 \%$

Test for overall effect: $z=0.71, P=0.47$
$1.4(11.50) / 38 \quad 2.0(11.93) / 38$

$0.5(2.37) / 35 \quad 1.4(2.37) / 35$

$1.9(2.40) / 36 \quad 1.6(2.30) / 34$

$3.0(9.17) / 5 \quad-2.0(8.54) / 7$

$-3.0(11.40) / 15 \quad-2.0(8.00) / 13$

127

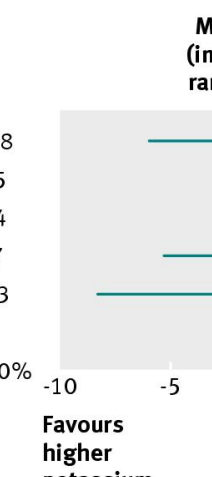

higher
Mean difference

(inverse variance,

random) $(95 \% \mathrm{Cl})$

\section{Weight Mean difference \\ (\%) (inverse variance, \\ random $)(95 \% \mathrm{Cl})$}

$2.10 \quad-0.60(-5.87$ to 4.67$)$

$47.70-0.90(-2.01$ to 0.21$)$

$48.50 \quad 0.30(-0.80$ to 1.40$)$

$0.60 \quad 5.00(-5.23$ to 15.23$)$

$1.10-1.00(-8.22$ to 6.22$)$

$100.00-0.28(-1.05$ to 0.49$)$

Fig 6 Effect of increased potassium intake on resting systolic blood pressure in children. Sinaiko 1993 reported results for boys and girls separately, and Wilson 1996 reported results for two groups separately on basis of their change in blood pressure between waking and sleeping hours during pilot phase of study 